Ocean Sci. Discuss., https://doi.org/10.5194/os-2017-53

Manuscript under review for journal Ocean Sci.

Discussion started: 1 August 2017

\title{
Definitive evidence of the Mediterranean Outflow heterogeneity. Part 2: all along the Strait of Gibraltar
}

\author{
Claude Millot \\ 5 Les Katikias, 83150 Bandol, France, \\ Correspondence to: Claude Millot (ailesetiles@gmail.com)
}

Abstract. We have demonstrated in Part 1, with only a CTD transect across the Strait at $6^{\circ} 05^{\prime} \mathrm{W}$, that the Mediterranean Outflow (MO) was definitely heterogeneous there. A yo-yo CTD time series has also provided

10 astounding examples of both the marked layering that the Mediterranean Waters (MWs) display on the vertical at the Strait entrance $\left(5^{\circ} 43^{\prime} \mathrm{W}\right)$, i.e. just upstream from the Camarinal sills $\left(5^{\circ} 45^{\prime} \mathrm{W}\right)$, as well as the tremendous instability processes occurring in all layers. We focus herein on similar data collected within the Strait at both $5^{\circ} 50^{\prime} \mathrm{W}$ and $6^{\circ} 05^{\prime} \mathrm{W}$ (downstream from the Camarinal and Espartel sills, resp.) during five campaigns of the 1985-1986 GIBEX. We first show additional transects supporting the demonstration we made at $6^{\circ} 05^{\prime} \mathrm{W}$, and we

15 demonstrate that the marked heterogeneity of the MO within the Strait is clearly on the horizontal; as we expected, densest (resp. lightest) MWs flow on the bottom on its left-hand (resp. right-hand) side and all MWs are juxtaposed side by side. We also demonstrate that the density range within the MO in the western side of the Strait $\left(6^{\circ} 05^{\prime} \mathrm{W}\right)$ is at least $0.5 \mathrm{~kg} \cdot \mathrm{m}^{-3}$, which is the density range, in the vicinity of the Cape St Vincent $\left(8^{\circ} 30^{\prime} \mathrm{W}\right)$, of the four veins formed by the MO splitting. We show that the lightest component of the MO has started to be split as soon as Camarinal sills and sink all along the Strait. The splitting of the MO into veins is thus mainly due to its intrinsic heterogeneity, which is a direct consequence of the Sea functioning and of the mixing, within the Strait itself, of the MO with this or that type of Atlantic Waters (AWs). Therefore, the bathymetry in the Strait, and even in the Strait exit surroundings (near $6^{\circ} 20^{\prime} \mathrm{W}$ ), has no major effect on the MO characteristics in the whole Ocean. We also focus on a yo-yo CTD time series collected during $\sim 24 \mathrm{~h}$ at $6^{\circ} 05^{\prime} \mathrm{W}$ which shows that markedly different MWs have been passing by, clearly demonstrating that the horizontally heterogeneous MO is significantly meandering within the Strait. Finally, we confirm one of our previous results that, provided the temporal variabilities of both the MWs and the AWs are not too large, significant relationships can possibly be established between the characteristics of the MWs at the Strait extremities, or at least that the slope of the mixing lines on a q-S diagram provides significant information. Parts 1 and 2 of our trilogy must be assimilated before reading Part 3.

Keywords: Strait of Gibraltar, Mediterranean Outflow, heterogeneity, Mediterranean Waters 
Ocean Sci. Discuss., https://doi.org/10.5194/os-2017-53

Manuscript under review for journal Ocean Sci.

Discussion started: 1 August 2017

(c) Author(s) 2017. CC BY 4.0 License.

2. The MO heterogeneity from cross-Strait transects 6

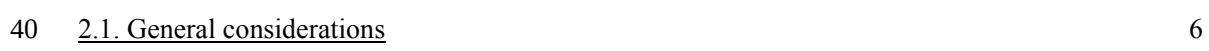

2.2. The LYN and GIB Transects $\quad 8$

2.2.1. At $6^{\circ} 05^{\prime} W$ (Nov. 15, 1985) 8

2.2.2. At $5^{\circ} 50^{\prime} W$ (Nov. 13-14, 1985) 10

2.2.3. At $5^{\circ} 50^{\prime} W$ (Nov. 3, 1985) 13

45 2.2.4. At $6^{\circ} 05^{\prime} W$ (Nov. 1-2, 1985) 15

2.2.5. At 5०50'W (Apr. 18-19, 1986) 17

2.2.6. At $6^{\circ} 05^{\prime} W(A p r .19,1986) \quad 19$

2.2.7. At $5^{\circ} 50^{\prime} W($ Sep. 29, 1986) 21

2.2.8. At $6^{\circ} 05^{\prime} W$ (Sep. 26, 1986) 23

$50 \quad$ 2.2.9. At $5^{\circ} 50^{\prime} W($ Jun. 19, 1986) 24

2.2.10. At $6^{\circ} 05^{\prime}$ W (Jun. 18-19, 1986) 26

3. The MO heterogenity from the LYN3 yo-yo CTD time series at $35^{\circ} 50^{\prime} \mathrm{N}-6^{\circ} 05^{\prime} \mathrm{W}$

3.1 The three groups $\quad 28$

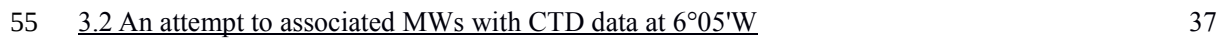

4. Discussion $\quad 42$

4.1 The overall density range of the MO

4.2 The long-term hydrological changes and the MO composition $\quad 42$

$\begin{array}{lll}60 & 4.3 \text { The MO variability within the Strait } & 43\end{array}$

$\begin{array}{ll}\text { 5. Conclusion } & 44\end{array}$

Acknowledgments $\quad 46$

65 References $\quad 46$ 
Ocean Sci. Discuss., https://doi.org/10.5194/os-2017-53

Manuscript under review for journal Ocean Sci.

Discussion started: 1 August 2017

(c) Author(s) 2017. CC BY 4.0 License.

\section{Introduction}

The Mediterranean Sea is a machine which, thanks to evaporation exceeding precipitation and river runoff over and all around the Sea, transforms waters from the Atlantic Ocean (AWs) inflowing at the surface, through the relatively narrow $(\sim 10 \mathrm{~km})$ and shallow $(\sim 300 \mathrm{~m})$ Strait of Gibraltar, into a set of intermediate (IWs) and deep (DWs) Mediterranean Waters (MWs). These MWs must exit from the Sea, hence forming the Mediterranean Outflow (MO) that has been shown for a while to be split into a series of veins, at least from the Strait exit. Because the MO is then identified in most of the northern Ocean, its splitting has received much attention but the MO has always been postulated to be relatively homogeneous upstream, if not from the Strait entrance (as in papers before the 2000's), at least within the Strait itself (as in 2015-2017 papers), the heterogeneity evidenced there being just considered as natural variability. And strangely, considering the dramatic importance and tremendous interest of the processes involved in the splitting, neither a single in situ experiment nor a single theoretical analysis have ever been dedicated to it. With our own papers about the functioning of the Sea, and in particular with a series of papers dedicated to the Strait (since Millot et al., 2006) in which we have been providing sound arguments about the possible identification of different MWs all along the Strait, we have thus generated an actual and major controversy about the homogeneity vs. heterogeneity of the MO.

We have not been convincing enough since a 2015 paper specifies being now "... in good agreement with the previous study of Millot (2014b)", but also "While up to four MWs are spatially distinguishable east of the main sill of Camarinal in the Strait, most of their differentiating characteristics are eroded after flowing over this restrictive topography due to mixing. West of the sill, therefore, speaking of a unique Mediterranean Water seems more appropriate" (Naranjo et al., 2015). And Garcia-Lafuente et al. (2017) clearly claim that, even though IWs (resp. DWs) are found in the north (resp. south) of the Alboran just before the Camarinal sills (for reasons completely different from those we invoke), "the severe mixing and dissipation that takes place ... downstream ... blurs this spatial pattern and tends to form a rather mixed outflow ... in which the MWs are barely distinguishable". Consequently, it is not surprising that studies about the Strait exit, furthermore since mainly dealing with pure strait dynamics, assume a homogeneous MO there and within the Strait itself. Details are provided in the Background Sect. 2 of Part 1 but such an assertion is now clearly and definitively invalidated by the demonstration we made in Sect. 3 of Part 1 that we will support and complete herein.

We first propose (Sect. 2) additional examples of the MO heterogeneity within the Strait from five 1985-1986 GIBEX CTD cross-Strait transects at both 5 $50^{\prime} \mathrm{W}$ and $6^{\circ} 05^{\prime} \mathrm{W}$ (Fig.1a): LYN1 (1-3 Nov. 1985), LYN2 (13-15 Nov. 1985), GIB1 (18-19 Apr. 1986), LYN3 (18-19 Jun. 1986) and GIB2 (26-29 Sept. 1986). We focus on the deeper part of the $\theta$-S diagrams which all are relatively straight mixing lines within the Strait, what we evidenced in previous papers (e.g. Millot 2009, 2014a), and we emphasize the occurrence of relatively thick homogeneous layers lying on the bottom with markedly different $\theta-S-\sigma_{q}$ characteristics associated with different MWs that are thus roughly juxtaposed side by side. Now, focusing on the deeper parts of the $\theta$-S diagrams must be done without forgetting the tremendous variability induced by the occurrence, in either parts or the totality of 
Ocean Sci. Discuss., https://doi.org/10.5194/os-2017-53

Manuscript under review for journal Ocean Sci.

Discussion started: 1 August 2017

(C) Author(s) 2017. CC BY 4.0 License. Water (NACW), as shown in Fig.1b. Moreover, MWs can mix with either the base of SAW, as on 7-8 Nov.1985, or with its upper part, as on 13-14 Nov. 1985, that is just a week apart and nearly at the same location in the eastern side of the Strait. Note that the scale $\Delta \theta / \Delta \mathrm{S}$ in Fig. $1 \mathrm{~b}\left((14.6-12.6) /(38.5-35.5)=2 / 3{ }^{\circ} \mathrm{C}\right)$ is different from the scale of all other figures below that is $1{ }^{\circ} \mathrm{C}$, for both Sect. $2\left((13.6-12.8) /(38.55-37.75)=0.8 / 0.8{ }^{\circ} \mathrm{C}\right)$ and Sect.

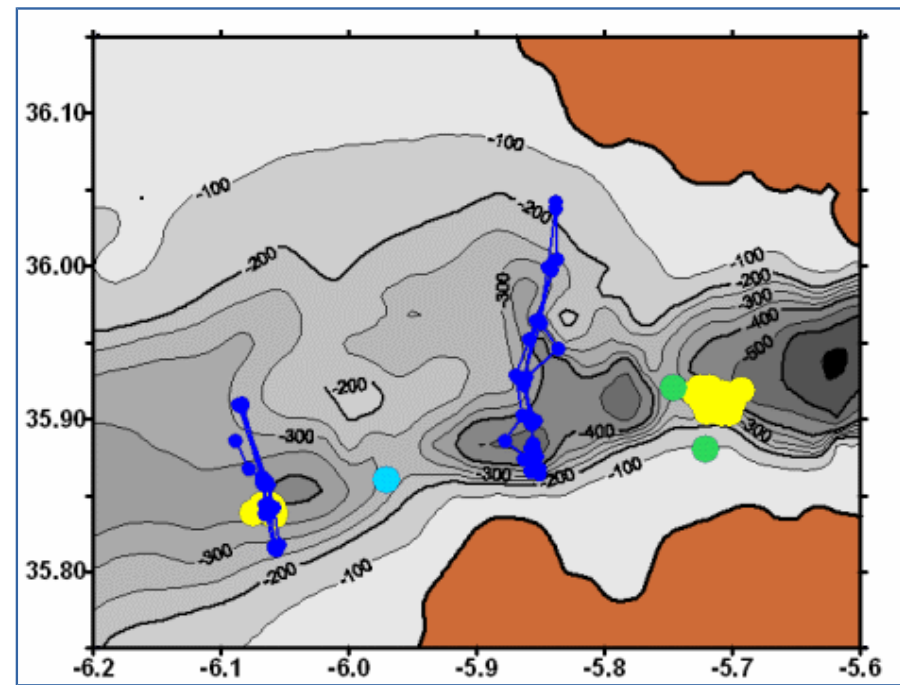

Figure 1a. Bathymetry $(\mathrm{m})$ of the studied area covering both the Strait of Gibraltar itself and its entrance, from $5^{\circ} 45^{\prime} \mathrm{W}(-5.75)$, in the western Alboran sub-basin. The five north-south CTD transects at $\sim 5^{\circ} 50^{\prime} \mathrm{W}$ and $6^{\circ} 05^{\prime} \mathrm{W}$ are indicated in dark blue. The two yo-yo CTD time series at $35^{\circ} 55^{\prime} \mathrm{N}-5^{\circ} 43^{\prime} \mathrm{W}$ (mainly analyzed in Part 1) and $35^{\circ} 50^{\prime} \mathrm{N}-6^{\circ} 05^{\prime} \mathrm{W}$ (analyzed herein) are located in yellow and displayed in Fig. $1 \mathrm{~b}$. The moored CTD time series from HYDROCHANGES are located in green for both the southern Camarinal sill $\left(5^{\circ} 45^{\prime} \mathrm{W}\right)$ and the southern continental shelf $\left(5^{\circ} 43.5^{\prime} \mathrm{W}\right)$, and in light blue for the southern Espartel sill $\left(5^{\circ} 59^{\prime} \mathrm{W}\right)$. The positions of the 19851986 GIBEX profiles (transects and yo-yo time series) were estimated from radar measurements. 
Ocean Sci. Discuss., https://doi.org/10.5194/os-2017-53

Manuscript under review for journal Ocean Sci.

Discussion started: 1 August 2017

(C) Author(s) 2017. CC BY 4.0 License.

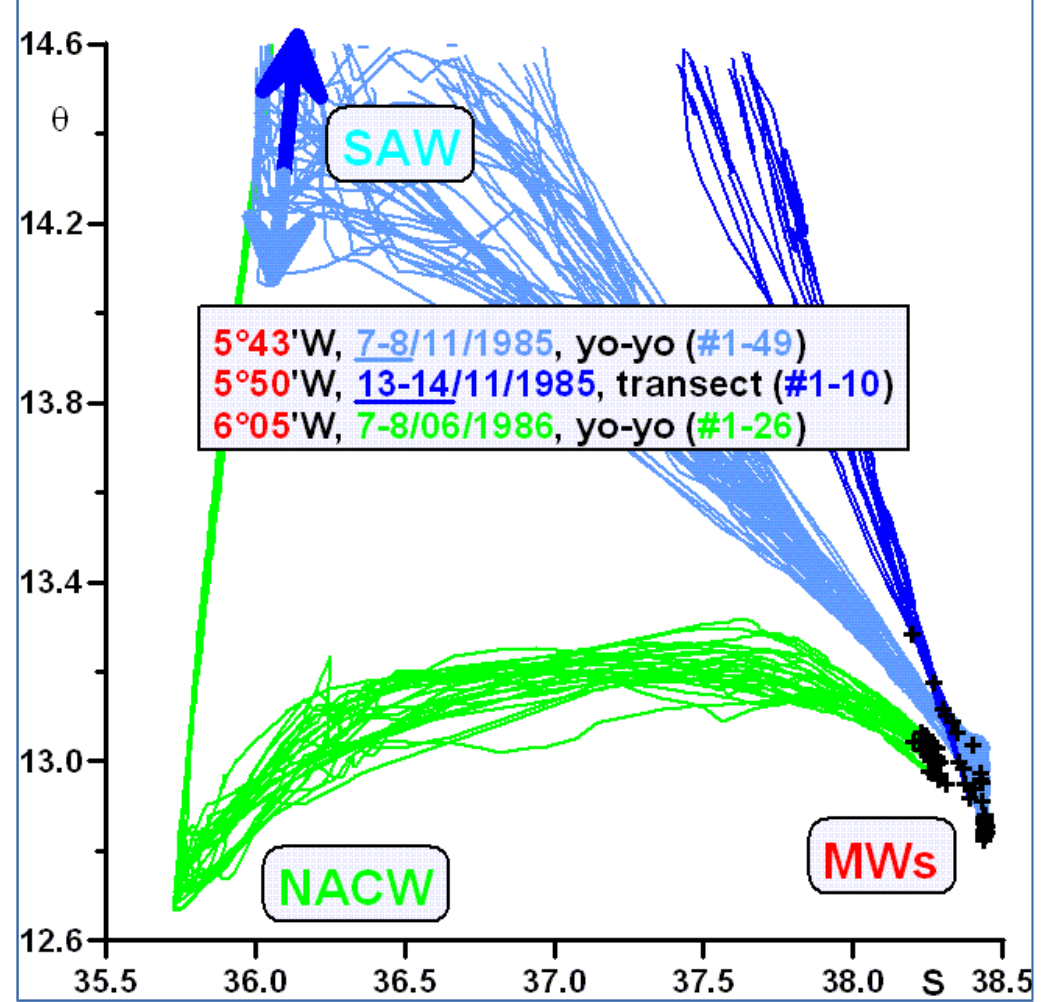

Figure 1b. Typical examples of the AWs-MWs mixing lines from the data sets analyzed herein. The MWs can mix with either the upper part or the lower part of SAW as well as with NACW only; mixing sometimes also occurs with the SAW-NACW interface (depleted from any profiles in this figure). Note the extremely large variability of the MO characteristics possibly encountered few days apart (already analyzed in Millot, 2008) as well as the fact that mixing with the NACW is generally more frequent and intense in the western side of the Strait; but such a variability is expected everywhere in the Strait.

We then propose (Sect. 3) a detailed analysis of a Jun. 1986 one-day yo-yo time series consisting in 26 CTD vertical profiles near $35^{\circ} 50^{\prime} \mathrm{N}-6^{\circ} 05^{\prime} \mathrm{W}$, which is downstream from the Espartel southern sill $\left(5^{\circ} 58.5^{\prime} \mathrm{W}\right)$, as we did in Part 1 for a Nov. 1985 one-day yo-yo time series consisting in 49 CTD profiles near $35^{\circ} 55^{\prime} \mathrm{W}-5^{\circ} 43^{\prime} \mathrm{W}$, which is just upstream of the Camarinal southern sill $\left(5^{\circ} 45^{\prime} \mathrm{W}\right)$. Both data sets are displayed in Fig. $1 \mathrm{~b}$. 
Ocean Sci. Discuss., https://doi.org/10.5194/os-2017-53

Manuscript under review for journal Ocean Sci.

Discussion started: 1 August 2017

(c) Author(s) 2017. CC BY 4.0 License.

2 The MO heterogeneity from cross-Strait transects

\subsection{General considerations}

We discuss the five sets of GIBEX CTD cross-Strait transects at $5^{\circ} 50^{\prime} \mathrm{W}$ and $6^{\circ} 05^{\prime} \mathrm{W}$ in an order that is the most appropriate to link the previous analyzes (Part 1) to the following ones (Sect. 2.2), while also trying to present examples of the MO heterogeneity with increasing complexity. All these $\theta$-S diagrams have been analyzed and displayed in the whole AWs-MWs range in Millot (2008, 2009), as in Fig.1b, and are displayed below with a focus on the MWs. In that range, and as already shown by e.g. Fig. 2 in Part 1, all these $\theta$-S diagrams are relatively straight mixing lines between a given AW and a unique MW lying on the bottom that, hence, cannot be directly compared with other MWs that would have been observed above. In addition, mixing with different AWs has more or less modified at least the upper part of these MWs, profiles did not reach the bottom for sure (the CTD was seemingly not equipped with any acoustic device), distance between the maximum depth and the bottom is unknown and profiles of any parameter $\left(\theta, S, \sigma_{q}\right)$ are similar while being less informative than at the Strait entrance. Consequently, maximum densities $\left(\sigma_{\max }\right)$ cannot be objectively quantified, classified and colored, as done in Part 1, furthermore these transects did not cover the whole Strait and sampling interval was too large to guarantee that all MWs have been sampled. We thus address the heterogeneity of the MO focusing on the homogeneity of the various MWs evidenced on the available profiles with an analysis of each profile at a 1-m/db or 2-m/db level (for the LYN or GIB campaigns, resp.) and we illustrate this homogeneity with the visual coloring of two sets of data, representing a more (cyan) or less (blue) homogeneous MW (details in Part 1), which allows specifying associated thicknesses. Some profiles evidence relatively thick (possibly $>200 \mathrm{~m}$ ) and homogeneous MWs while others only reach the upper part of a MW without evidencing any homogeneity (sign "_" in the thickness indication).

Now, to understand the characteristics of the mixing lines evidenced below, the basic example proposed as Fig.1 in Part 1 is not sufficient since the MWs are not static. While mixing with the AWs on the vertical, and be this mixing total or partial, they continuously flow with relatively large velocities (often in the order of the $\mathrm{m} \cdot \mathrm{s}^{-1}$ ) so that they simultaneously encounter, in particular over the bottom, an important turbulent mixing that will always tend to re-homogenize them. And since they generally flow at some given depth along a sloping bottom, furthermore against the AWs, hence with a sloping AWs-MWs interface, they get different although strongly related q-S- $\mathrm{S}_{\mathrm{q}}$ characteristics (Fig.1c). As long as the same AW and the same MO component (or MW as generally used herein) are concerned, the important point to note is that both the mixing and the rehomogenization occur along the same mixing line. In case the two AWs occur, the deepest part of the MO component, being less modified by its mixing with SAW than by its mixing with NACW, will be characterized by homogeneous (cyan) and nearly homogeneous (blue) layers having densities on profile \#2 larger than on profile \#1. In case only one AW occurs, hence giving two series of cyan and blue points along the same mixing line, even a MO that would be homogeneous at the Strait entrance would thus become heterogeneous within the Strait itself. 
Ocean Sci. Discuss., https://doi.org/10.5194/os-2017-53

Manuscript under review for journal Ocean Sci.

Discussion started: 1 August 2017

(c) Author(s) 2017. CC BY 4.0 License.

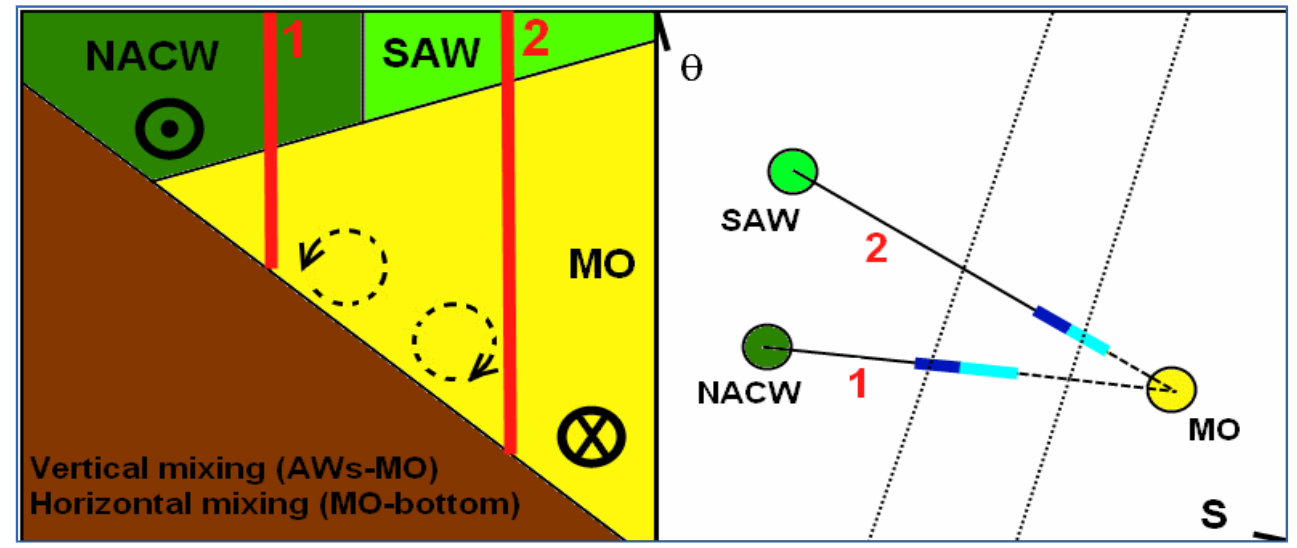

Figure 1c. Schematisation of CTD vertical profiles \#1 (across NACW and the MO) and \#2 (across SAW and the

$\mathrm{MO}$ ) in the southern part of the Strait, and the associated mixing lines in a q-S diagram (isopycnals as dotted lines); in that case, the MO is represented by its densest component, in general WDW (see below). 
Ocean Sci. Discuss., https://doi.org/10.5194/os-2017-53

Manuscript under review for journal Ocean Sci.

(C) Author(s) 2017. CC BY 4.0 License.

\section{(c) (1)}

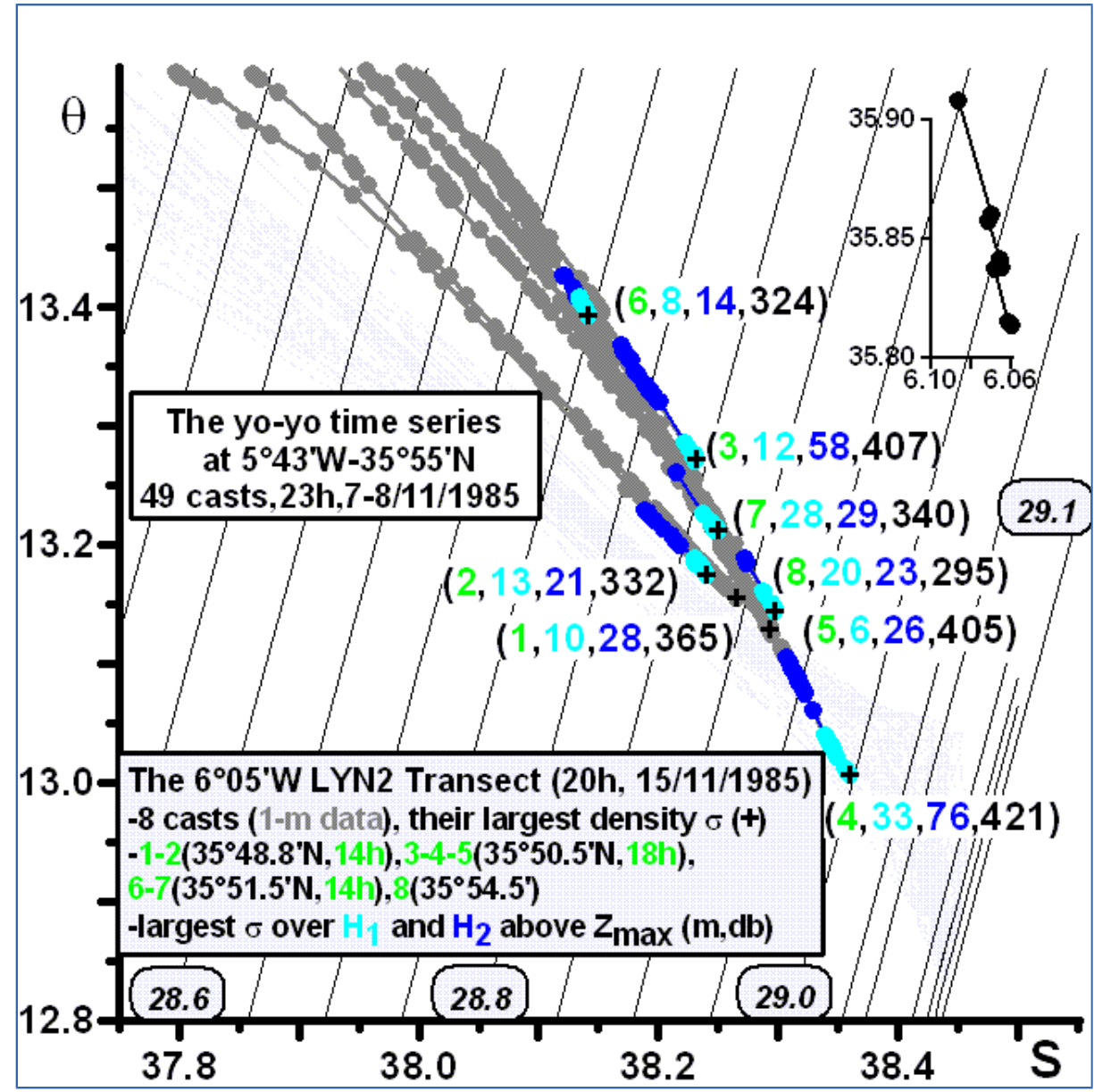

Figure 2a. $\theta$-S diagrams from the LYN2 transect at $6^{\circ} 05^{\prime} \mathrm{W}$ on $15 \mathrm{Nov} .1985$ performed twice within $10 \mathrm{~h}$ (shown as Fig.2 in Part 1). Locations of the profiles are specified both in the inserted diagram and in the legend while their numbering (in all our papers) along north-south transects is from south to north. Profiles have been analyzed at the 1-m (LYN) or 2-m (GIB) levels so that thicknesses indicated in either cyan or blue have been arbitrarily but accurately specified in $\mathrm{m}$ above the maximum depth (specified in black) reached by the profile: cyan dots (markedly homogeneous waters) are plotted over blue ones (less but still relatively homogeneous waters) so that blue thicknesses are always greater than cyan ones. Especially when relatively homogeneous layers are relatively thick, $\sigma_{\max }(+)$ are often found away from the bottom. For clarity of this specific figure, data for $\# 1$ and $\# 5$ have not been colored but thicknesses are similar to those of \#2. When two successive data cannot 
Ocean Sci. Discuss., https://doi.org/10.5194/os-2017-53

Manuscript under review for journal Ocean Sci.

Discussion started: 1 August 2017

(c) Author(s) 2017. CC BY 4.0 License.

evidence any homogeneous layer (not in this figure), the data are not colored and thicknesses values are

specified as "-".

This transect, performed a few days after the yo-yo time series at $5^{\circ} 43^{\prime} \mathrm{W}$ (on Nov. 7-8), was considered in Part 1 as the most suitable among the available transects so as to follow the MWs while they propagate from the Strait entrance to the western side of the Strait and demonstrate the heterogeneity of the MO there; but it only covers the southern side of the Strait and cannot provide an overview of the whole MO. Because it has been repeated twice in succession within $\sim 10 \mathrm{~h}$, it allows evidencing the marked variability encountered at any given specific place, even few h apart. Relatively homogeneous (cyan) waters are observed at the bottom on all profiles, sometimes over relatively large thicknesses $(33 \mathrm{~m}, 28 \mathrm{~m}, 20 \mathrm{~m})$, from very different sets of $\theta-\mathrm{S}-\sigma_{\theta}$ extreme values (the black crosses) that are distributed over relatively large ranges of $\sim 0.4^{\circ} \mathrm{C}, \sim 0.2 \mathrm{~S}$ units and $\sim 0.25 \mathrm{~kg} . \mathrm{m}^{-}$ ${ }^{3}$. The fact that these sets are distributed in a relatively sparse way obviously implies that actual ranges (in particular in the western side of the Strait) obtained with more samples would have been larger. In any event, we have indicated in Part 1 that general features, such as the dependency of the maximum density $\sigma_{\max }$, as well as $\mathrm{q}_{\min }$ and $\mathrm{S}_{\max }$, as a function of the cross-Strait location, were not retrieved on this transect, the specific features of which have already been mentioned; we thus do not detail them again. All other transects below generally display most of the general features we consider as significant. 
Ocean Sci. Discuss., https://doi.org/10.5194/os-2017-53

Manuscript under review for journal Ocean Sci.

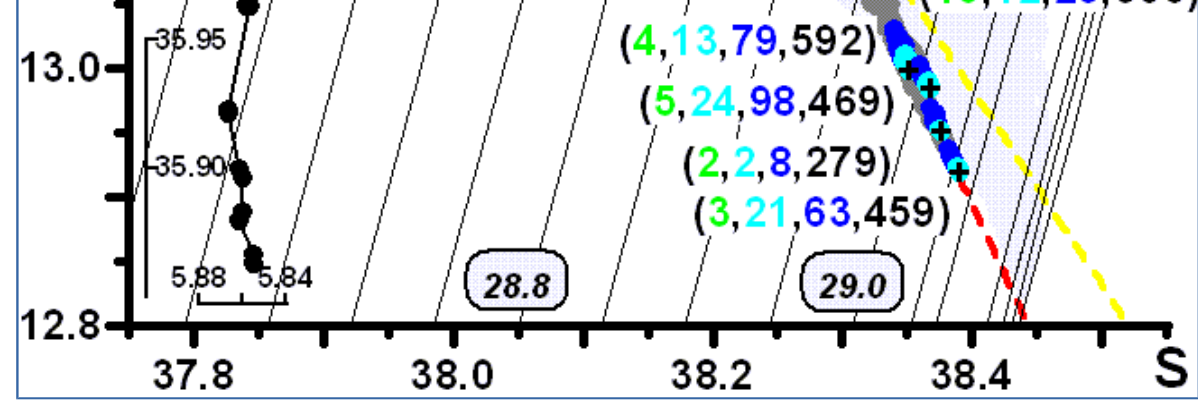

Figure 2b. Same as in Fig.2a for the LYN2 transect at 5 50'W performed twice within $16 \mathrm{~h}$ on 13-14 Nov. 1985. Profiles \#9 and \#10 are specified in black while fit to \#3 (resp. \#10) is specified by a dashed line in red (resp. yellow). The yo-yo time series at 5 $43^{\prime} \mathrm{W}$ on 7-8 Nov. 1985 is plotted in light gray.

First note that this profile does not extend north much more than $\sim 35.95^{\circ} \mathrm{N}$ so that it does not cover the northern side of the Strait (Fig.1a). Fig.2b clearly shows how dramatic has been the change in the slope of the AWs-MWs mixing lines at the two nearby locations of $5^{\circ} 43^{\prime} \mathrm{W}$ and $5^{\circ} 50^{\prime} \mathrm{W}$, just one week apart, as first evidenced in Fig. $1 \mathrm{~b}$. This is only due to the occurrence of different AWs, not to the Camarinal crossing: either AWs were permanently different at these two nearby locations or, more probably, the AWs changed within one week. At the Strait entrance $\left(5^{\circ} 43^{\prime} \mathrm{W}\right)$ and in the eastern side of the Strait itself $\left(5^{\circ} 50^{\prime} \mathrm{W}\right)$, the MO mixed with the base of the SAW on Nov. 7-8 and with the top of the SAW layer on Nov. 13-14 which, obviously, has dramatic consequences on the MO characteristics there and downstream. 
Ocean Sci. Discuss., https://doi.org/10.5194/os-2017-53

Manuscript under review for journal Ocean Sci.

Discussion started: 1 August 2017

(c) Author(s) 2017. CC BY 4.0 License.

The $5^{\circ} 50^{\prime} \mathrm{W}$ transect has also been repeated twice with the main objective to occupy locations as similar as possible ( $\sim 8 \mathrm{~h}$ apart), which should correspond to similar bottom depths. However, maximum depths (in $\mathrm{m}$ ) markedly vary from pair to pair (\#1-2 (186-279), \#3-4 (459-592), \#5-6 (469-444), \#7-8 (270-295) and \#9-10 (294-366)), so that even if each pair of profiles can be expected to have sampled the same MW (what will be shown not to be always the case), they have sampled these MWs in different cross-slope positions as schematized in Fig.1c. Which leads to apparently complex features considering, for instance, the very different $\mathrm{S}_{\max }$ values of profiles \#1 (one of the lowest values) and \#2 (one of the largest values) that depict in fact the same MW. Indeed, actual \#1 and \#2 occupy exactly the position theoretical 1 and 2 occupy in Fig. $1 \mathrm{c}$ with a unique $\mathrm{AW}$, hence with the same mixing line. In case of a homogeneous $\mathrm{MO}$ outflowing below a unique $\mathrm{AW}$ across the whole V-shape section of the Strait, both vertical mixing and homogenization due to bottom friction would lead to the creation of a MO core in the deepest part of the Strait. In case of a unique homogeneous MW outflowing below a unique AW over only a portion of one or the other slope, a MW core will also be created close to its deeper part, while deepest profiles will evidence a MW more mixed with the neighbor MW. Furthermore the MWs entering the Strait are not fully homogeneous, the main result of the processes schematized in Fig.1c is that a core will always be created for all the MWs and that each of the MWs will display a relatively large range of q$\mathrm{S}-\mathrm{S}_{\mathrm{q}}$ values that cannot be used alone to characterize these MWs.

All the general features of this transect have been considered as significant in our previous papers:

i) \#1-2: \#1 being by far the shallowest (186 m) of all profiles sampled only the very upper part of the MO (in fact of its southernmost component). Being much shallower (hence more to the south) than \#2 (279 m), and \#2 evidencing a relatively large $\sigma_{\max }$, it must be assumed that both sampled the densest of the MWs expected there, and that \#2 was closer to the core.

ii) \#3-4: in the same way, both sampled the same MW that, considering the similarity of the mixing lines slopes and associated sets of q-S-S $\mathrm{q}_{\mathrm{q}}$ values, is probably the same as the MW sampled by \#1-2. Profile \#3 (459 m) evidenced the largest $\sigma_{\max }$ and was thus the closest to this MW's core and \#4, being much deeper (592 m) than \#3 (and the closest to the deepest part of the Strait) clearly sampled the lower part of this MW. The densest of the MWs, probably WDW, has thus been sampled by \#1-2 in its upper part, by \#3 near to its core and by \#4 in its lower part, as flowing essentially along the southern slope and as the densest component of the MO (probably WDW).

iii) \#5-6: even though both are located above the northern continental slope (greater depths were reached at \#4), \#5 resembles \#1-2-3-4 and is markedly different from \#6, in both the mixing line slope and the $\theta-S-\sigma_{q}$ values. It is clear that \#5 and \#6 did not sample the same MW, be this due either to different positions (of the CTD $\sim 8 \mathrm{~h}$ apart; note that ship positions were also a bit different) at the ends of the \#5 and \#6 downcasts and/or to the occurrence of different MWs where the CTD actually was.

iv) \#7-8: both profiles, as well as bottom depths, are relatively similar. Most probably, they have been performed at similar locations (or at least along similar isobaths) and the MW they sampled did not markedly change. Since the same MW was seemingly sampled at \#6, much deeper and more to the south, it might be that all sampled a still relatively dense and voluminous MW (probably EDW). 
Ocean Sci. Discuss., https://doi.org/10.5194/os-2017-53

Manuscript under review for journal Ocean Sci.

Discussion started: 1 August 2017

(c) Author(s) 2017. CC BY 4.0 License.

v) \#9-10: even though mixing line slopes are similar, both are significantly different from the slopes of all the other profiles: it is clear that the MO mixed with a given AW at locations 1-2 to 7-8, i.e. in the southern side of the Strait, and with another AW at locations 9-10, i.e. in the middle of the Strait. However, while \#10 resembles to \#6-7-8 (\#6 being very far to the south of \#10), so that all four profiles sampled the same relatively homogeneous MW with \#10 being the closest to its core, \#9 only sampled the upper part of that MW; this is another example of the tremendous spatio-temporal variability previously emphasized. In any event, note (Fig.1a) that isobaths in the relatively large domain covered by profiles \#6 to \#10 are mainly aligned north-south and indicate a relatively steep bottom slope: such bathymetric features of relatively small scale certainly constrain the MO component flowing there to modify its direction, hence flowing more along than across this north-south/cross-Strait transect, which would lead to sampling the same MW from \#6 to \#10.

Note that while \#1 clearly sampled the upper part of the MO in the southern side of this transect at $5^{\circ} 50^{\prime} \mathrm{W}$ on 13-14 Nov. 1985, other transects shown below will confirm that the northern side of the MO was not sampled: transects limited to such relatively low latitudes provide a description of the MO that is clearly truncated. Also note the interesting information provided in Fig.2b by the fits to the \#3 (red) and \#10 (yellow) diagrams in the displayed ranges. While profiles such as e.g. $\# 10$ (at $35^{\circ} 58^{\prime} \mathrm{N}-5^{\circ} 50^{\prime} \mathrm{W}$ ) could clearly be obtained from mixing of a given $\mathrm{MW}$ at $35^{\circ} 55^{\prime} \mathrm{N}-5^{\circ} 43^{\prime} \mathrm{W}$ with a given $\mathrm{AW}$, a profile such as e.g. $\# 3$ (at $35^{\circ} 53^{\prime} \mathrm{N}-5^{\circ} 50^{\prime} \mathrm{W}$ ) could probably not. This is surprising because Fig. 1a indicates that current lines associated with the MO at the $5^{\circ} 43^{\prime} \mathrm{W}$ yo-yo location (on Nov. 7-8) are expected to pass then over \#1-5 more easily than over \#9-10. It must thus be hypothesized from Fig.2b that, while crossing the Camarinal sills in particular, the densest MWs sampled at $5^{\circ} 53^{\prime} \mathrm{W}$ have first mixed with the base of SAW just after Nov. 7-8, hence first shifting $\theta-\mathrm{S}$ values in the direction of the time series mixing lines, before mixing with the top of SAW on and/or just before Nov. 13-14, then shifting $\theta-\mathrm{S}$ values in the direction of the \#1-5 mixing lines. 
Ocean Sci. Discuss., https://doi.org/10.5194/os-2017-53

Manuscript under review for journal Ocean Sci.

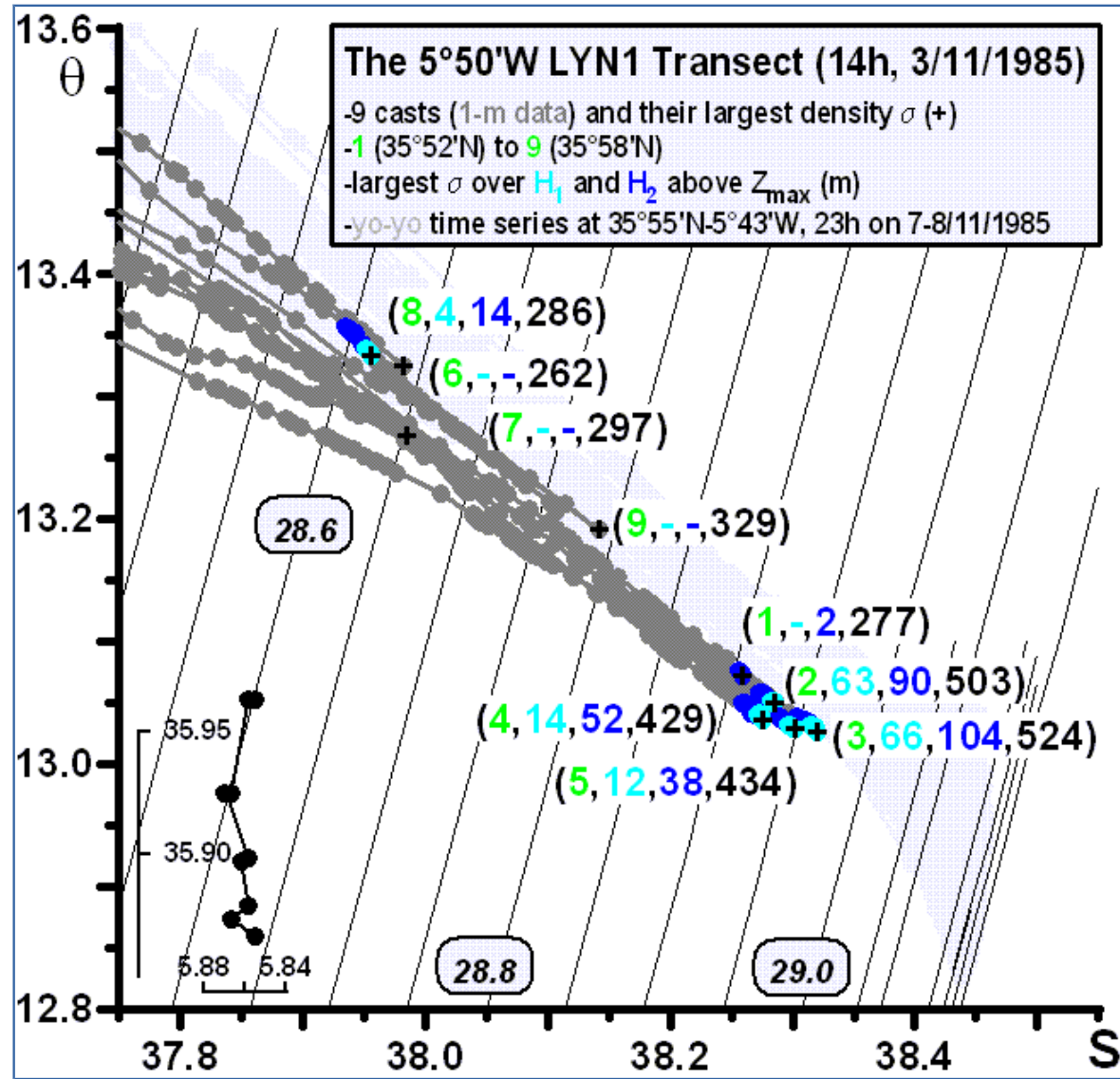

Figure 2c. Same as in Fig.2a for the LYN1 transect at $5^{\circ} 50^{\prime} \mathrm{W}$ on 3 Nov. 1985 . The yo-yo time series at $5^{\circ} 43^{\prime} \mathrm{W}$ is plotted in light gray.

What we just hypothesized is clearly demonstrated by Fig.2c which displays the $\theta$-S diagrams at $5^{\circ} 50^{\prime} \mathrm{W}$ on Nov. 3 nearly at the locations occupied 10 days later as shown in Fig. $2 \mathrm{~b}$ : during both the $5^{\circ} 50^{\prime} \mathrm{W}$ transect on Nov. 3 and the yo-yo time series at $5^{\circ} 43^{\prime} \mathrm{W}$ on Nov. 7-8, the MO mixed with the base of SAW that thus occupied the whole area during the whole period. Correspondence between the two sets of diagrams is straightforward and the stable conditions in the AWs layer, at least in this portion of the Strait, demonstrate that the densest MWs sampled at $5^{\circ} 43^{\prime} \mathrm{W}$ (in particular WDW) were not sampled by the transect (or, eventually, that they did not overflow). Note that \#1, 2 and 3 were at markedly different locations while positions of \#4-5, \#6-7 and \#8-9 are relatively similar. Also note that \#1 only reached the upper part of the MO while both \#2 and \#3 (close to the deepest part of the Strait) allowed evidencing a relatively thick $(\sim 100 \mathrm{~m})$ and homogeneous MW that was also sampled, with a reduced thickness, more to the north at \#4-5. The same relatively thick and homogeneous MW 
Ocean Sci. Discuss., https://doi.org/10.5194/os-2017-53

Manuscript under review for journal Ocean Sci.

Discussion started: 1 August 2017

(c) Author(s) 2017. CC BY 4.0 License.

415 thus occupied the whole Strait section below $\sim 400 \mathrm{~m}$ (bottom-depth minus blue-thickness value). Furthermore no homogeneous MW was sampled at \#6-7-9, \#2-3-4-5 could evidence some kind of homogeneous MO.

However, \#8 evidences a relatively light $\left(\sigma_{\max } \sim 28.6 \mathrm{~kg} \cdot \mathrm{m}^{-3}\right)$ and homogeneous MW as do other transects that extend more to the north. This transect is thus a clear example of the misunderstanding that such a truncated sampling (in that case not south enough since \#1 was performed over depths of $\sim 277 \mathrm{~m}$ while a homogeneous

420 MW has been evidenced over depths of $\sim 186 \mathrm{~m}$, as \#1 in Fig.2b), hence information, could give (has clearly given) for what concerns the MO consistency. 
Ocean Sci. Discuss., https://doi.org/10.5194/os-2017-53

Manuscript under review for journal Ocean Sci.

Discussion started: 1 August 2017

(C) Author(s) 2017. CC BY 4.0 License.

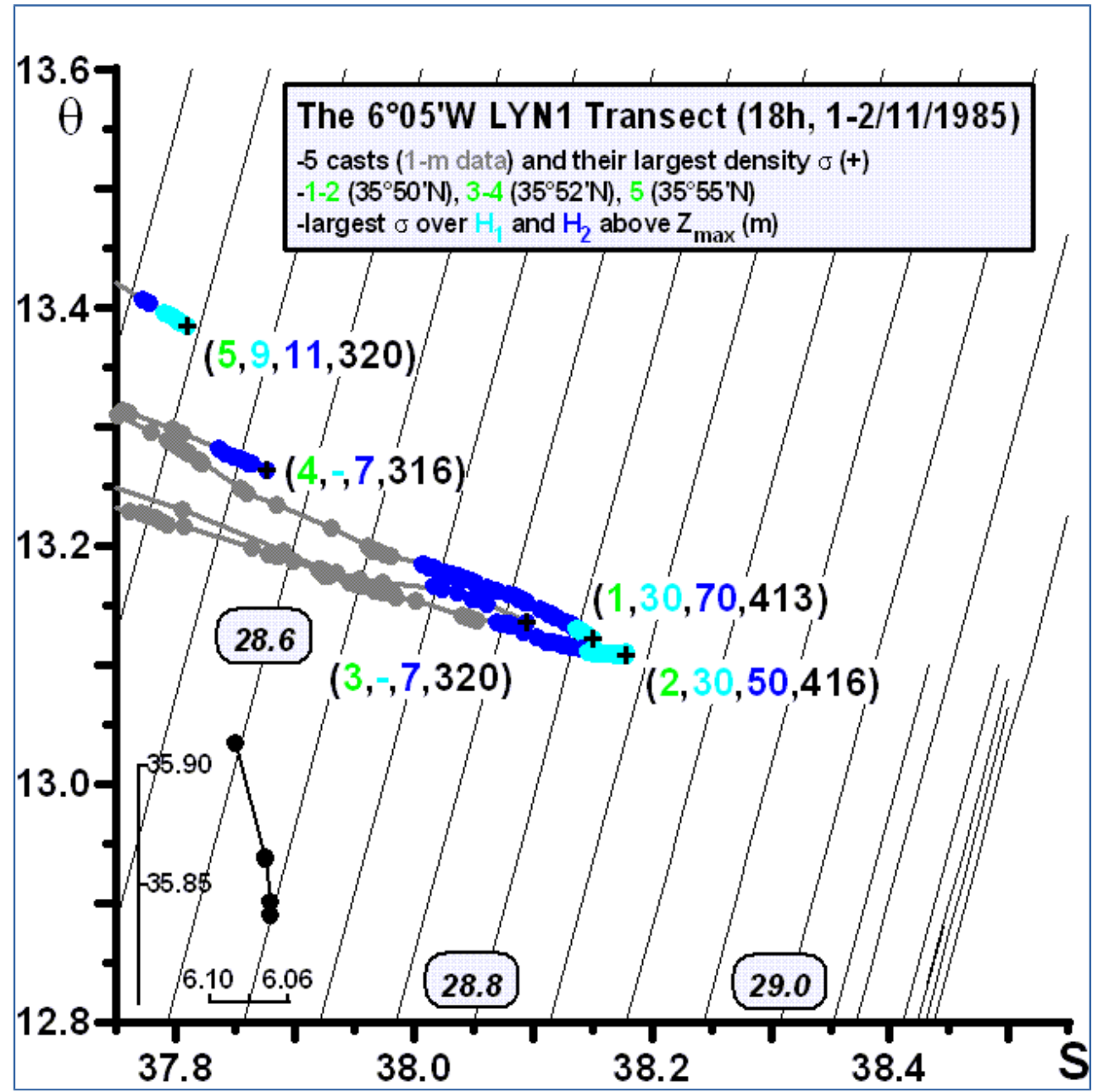

Figure 2d. Same as in Fig.2a for the LYN1transect at 6 $05^{\prime} \mathrm{W}$ on 1-2 Nov. 1985.

Features relatively similar to those above described (at $5^{\circ} 50^{\prime} \mathrm{W}$, Fig.2c) were observed one day before more downstream (at $6^{\circ} 05^{\prime} \mathrm{W}$, Fig.2d). Profiles \#1-2 evidence the same relatively homogeneous and still relatively thick ( $\sim 60 \mathrm{~m}$ ) MW that was sampled only in its upper part by \#3-4. But, again, the southernmost \#1-2 are over depths of 410-420 $\mathrm{m}$ at $\sim 35^{\circ} 50^{\prime} \mathrm{N}$, hence clearly missing the southern side of the MO. In addition, comparison with the same transect on Nov. 15 (Fig.2a) performed just $\sim 2$ weeks after, in particular with \#4 obtained exactly at the same place $\left(420 \mathrm{~m}, \sim 35.50 .5^{\prime} \mathrm{N}\right)$, illustrates the tremendously large temporal variability in the western side of the Strait: on Nov. 1-2 and Nov. 15, both mixing lines slopes and $\sigma_{\max }$ values (28.80-28.85 vs. $\left.29.0 \mathrm{~kg} . \mathrm{m}^{-3}\right)$ were markedly different. A similar comparison between Fig.2d and Fig.2a evidences a relatively light and 
Ocean Sci. Discuss., https://doi.org/10.5194/os-2017-53

Manuscript under review for journal Ocean Sci.

Discussion started: 1 August 2017

(c) Author(s) 2017. CC BY 4.0 License.

homogenous ( $\sim 10 \mathrm{~m}$ thick) MW layer with $\sigma_{\max } \sim 28.5 \mathrm{~kg} \cdot \mathrm{m}^{-3}$ (at $\# 5,320 \mathrm{~m}, 35^{\circ} 55^{\prime} \mathrm{N}$ ) on Nov. $1-2$ and $\sigma_{\max } \sim$ $28.75 \mathrm{~kg} \cdot \mathrm{m}^{-3}$ (at \#6, $324 \mathrm{~m}, 35^{\circ} 51.5^{\prime} \mathrm{N}$ ) on Nov. 15. Even though this might be the same MW sampled at different latitudes, hence at different positions with respect to its core, on can retain for sure that the maximum $\mathrm{Ds}_{\mathrm{q}}$ characterizing the $\mathrm{MO}$ heterogeneity at $6^{\circ} 05^{\prime} \mathrm{W}$ is, at least (because of the incomplete sampling of the MO), 0.5 $\mathrm{kg} \cdot \mathrm{m}^{-3}(29.0-28.5)$. Furthermore similar extrema will be measured during the other transects described below, hence at different periods of time, and even with a too coarse sampling, it is definitively demonstrated that the actual $\sigma_{\max }$ range in the western side of the Strait is clearly at least in the order of the $\sigma_{\max }$ range presently assumed between the four veins south of Cape St Vincent $\left(0.55 \mathrm{~kg} \cdot \mathrm{m}^{-3}\right)$. 
Ocean Sci. Discuss., https://doi.org/10.5194/os-2017-53

Manuscript under review for journal Ocean Sci.

(C) Author(s) 2017. CC BY 4.0 License.

\section{(c) (i)}

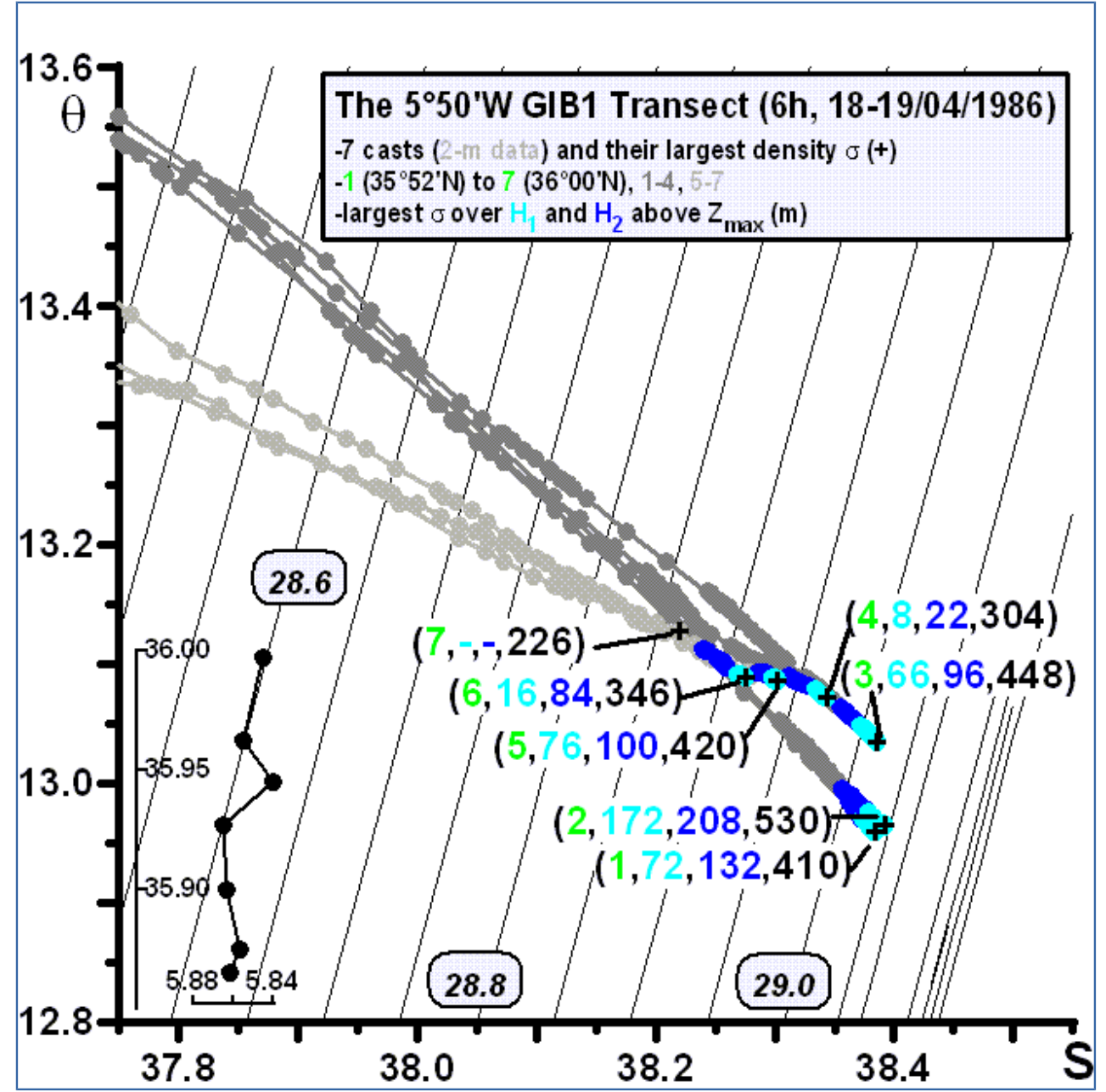

Figure 2e. Same as in Fig.2a for the GIB1 transect at 550'W on 18-19 Apr. 1986. Profiles \#1-2-3-4 in dark gray and \#5-6-7 in mild gray.

This transect, performed $\sim 6$ months after the transects displayed in Fig. $2 \mathrm{~b}, 2 \mathrm{c}$ extends a bit more to the north and it was not repeated. Note that, while \#1-2-3-4 indicate a mixing of the MO with the base of the SAW layer, \#5-67 indicate a mixing with what can be considered either as a not well marked NACW or some kind of SAW-

$\mathrm{NACW}$ interface. Also note that the very thick (up to $200 \mathrm{~m}$ ) and very homogeneous MW clearly sampled by \#1-2 is markedly different from another MW sampled mainly by \#3 but also probably by \#4-5-6 more to the north. This transect might be the best example of:

i) the MO heterogeneity in the eastern side of the Strait ... even though only two MWs can be identified, which could be due to the possible non-occurrence of one of the other MWs evidenced in Part 1, or to a transect not 
Ocean Sci. Discuss., https://doi.org/10.5194/os-2017-53

Manuscript under review for journal Ocean Sci.

Discussion started: 1 August 2017

(c) Author(s) 2017. CC BY 4.0 License.

wide enough. Indeed, it is obvious that this transect did not sample neither the southern edge of the MO (\#1 here is over $410 \mathrm{~m}$ only) nor its northern edge (see below).

ii) the relative complexity of such a set of profiles: one MW is sampled by \#1-2 and another MW is sampled by \#3-4-5-6-7 (even if only slightly by \#7) while mixing occurs with one AW on \#1-2-3-4 and another AW on \#5-67. More generally, both the AWs and the MWs are roughly distributed in a north-south/cross-Strait direction, and always in the same way: NACW is always more to the south than SAW and the densest MWs are always more to the south than the lightest MWs. In the relatively simple case of two AWs mixing with two MWs, both being juxtaposed side by side and the vertical interfaces within both the AWs and the MWs do not having any a priori relationships, at least four types of mixing lines are expected; considering up to three types of AWs (Fig.1b) and up to five MWs (Part 1) could thus lead to a possible series of fifteen types of mixing line slopes. iii) the misunderstanding generated by a truncated information since the non-observation at the \#7 location $\left(\sim 36^{\circ} \mathrm{N}\right)$ of any homogeneous MW could lead to conclude that no other component of the MO can flow more to the north, contrary to what will be demonstrated below.

iv) the role of buffer zone played by the Strait eastern side that we cannot illustrate and comment but that must have a significant importance in the Strait functioning. Indeed, thicknesses of $\sim 200 \mathrm{~m}$ reached by some components of the MO there, at $5^{\circ} 50^{\prime} \mathrm{W}$ (Fig.2e, just west from Camarinal sills) as well as at $5^{\circ} 43^{\prime} \mathrm{W}$ (e.g. Fig.8 of Part 1, just east from Camarinal sills) are never retrieved downstream, neither at $\sim 6^{\circ} 05^{\prime} \mathrm{W}$ (herein) nor near $6^{\circ} 20^{\prime} \mathrm{W}$ at the Strait exit (Part 3), where maximum thicknesses are some tens of m only. Dramatic consequences are expected for both the hydrological and dynamical characteristics of these components that, necessarily, do not transit with a relatively constant velocity. 
Ocean Sci. Discuss., https://doi.org/10.5194/os-2017-53

Manuscript under review for journal Ocean Sci.

Discussion started: 1 August 2017

(c) Author(s) 2017. CC BY 4.0 License.

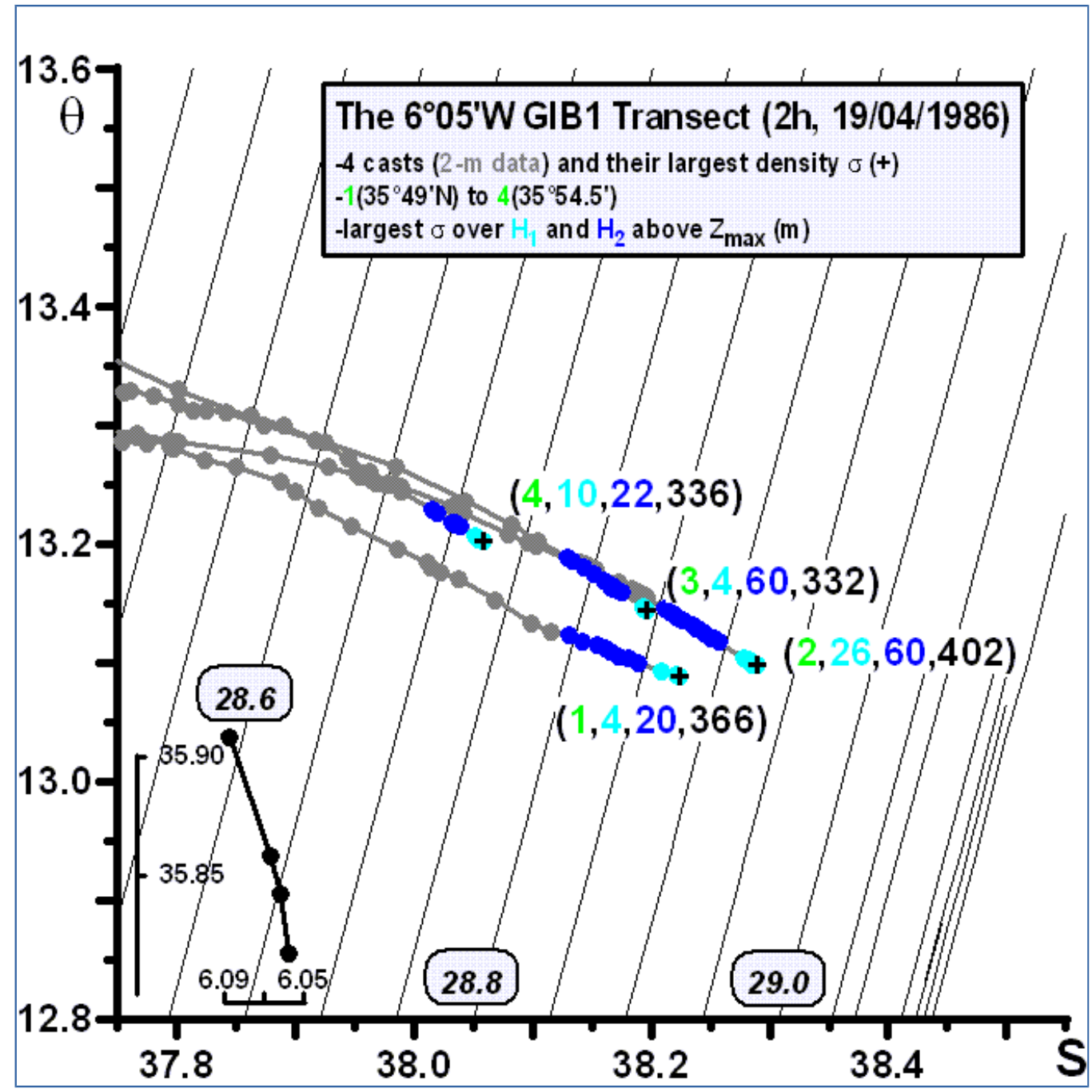

Figure 2f. Same as in Fig.2a for the GIB1 transect at 6º5'W on 19 Apr. 1986.

This transect is nearly simultaneous to the previous one at $5^{\circ} 50^{\prime} \mathrm{W}$ and it displays additional interesting features. Even though all mixing lines display a similar slope in these $\theta$ and $\mathrm{S}$ ranges, only $\# 4$ indicates, in the overall $\theta$ and $\mathrm{S}$ ranges, a mixing between the $\mathrm{MO}$ and the SAW-NACW interface while \#1-2-3 clearly indicate a mixing with NACW only. It is a general feature we already evidenced (e.g. Millot, 2014a) that NACW is always concentrated along the southern continental slope within the Strait, since it should significantly inflow into the 
Ocean Sci. Discuss., https://doi.org/10.5194/os-2017-53

Manuscript under review for journal Ocean Sci.

Discussion started: 1 August 2017

(c) Author(s) 2017. CC BY 4.0 License.

Sea and hence be submitted to the Coriolis effect, in particular in the western side of the Strait where it is less interacting with the MO.

Another interesting feature is that \#1 and \#2-3 mainly indicate two different MWs. Note that differentiating the

MWs is more or less clear and easy, depending on the slope of the mixing lines with the AWs: in the present case for instance, the \#1 and \#2 mixing lines would have been more easily differentiated if mixing of the MWs occurred with the top of the SAW layer (mixing lines would have been more perpendicular to the segment linking the \#1 and \#2 $\sigma_{\max }$ ). Now, it might be that the two MWs sampled at $5^{\circ} 50^{\prime} \mathrm{W}$ (Fig.2e, by \#1-2 and by \#3-4-

$5005-6-7$ ), were nearly simultaneously sampled at $6^{\circ} 05^{\prime} \mathrm{W}$ (Fig.2f, by $\# 1$ and by $\# 2-3-4$ ), but data in between are clearly missing. 
Ocean Sci. Discuss., https://doi.org/10.5194/os-2017-53

Manuscript under review for journal Ocean Sci.

Discussion started: 1 August 2017

(C) Author(s) 2017. CC BY 4.0 License.

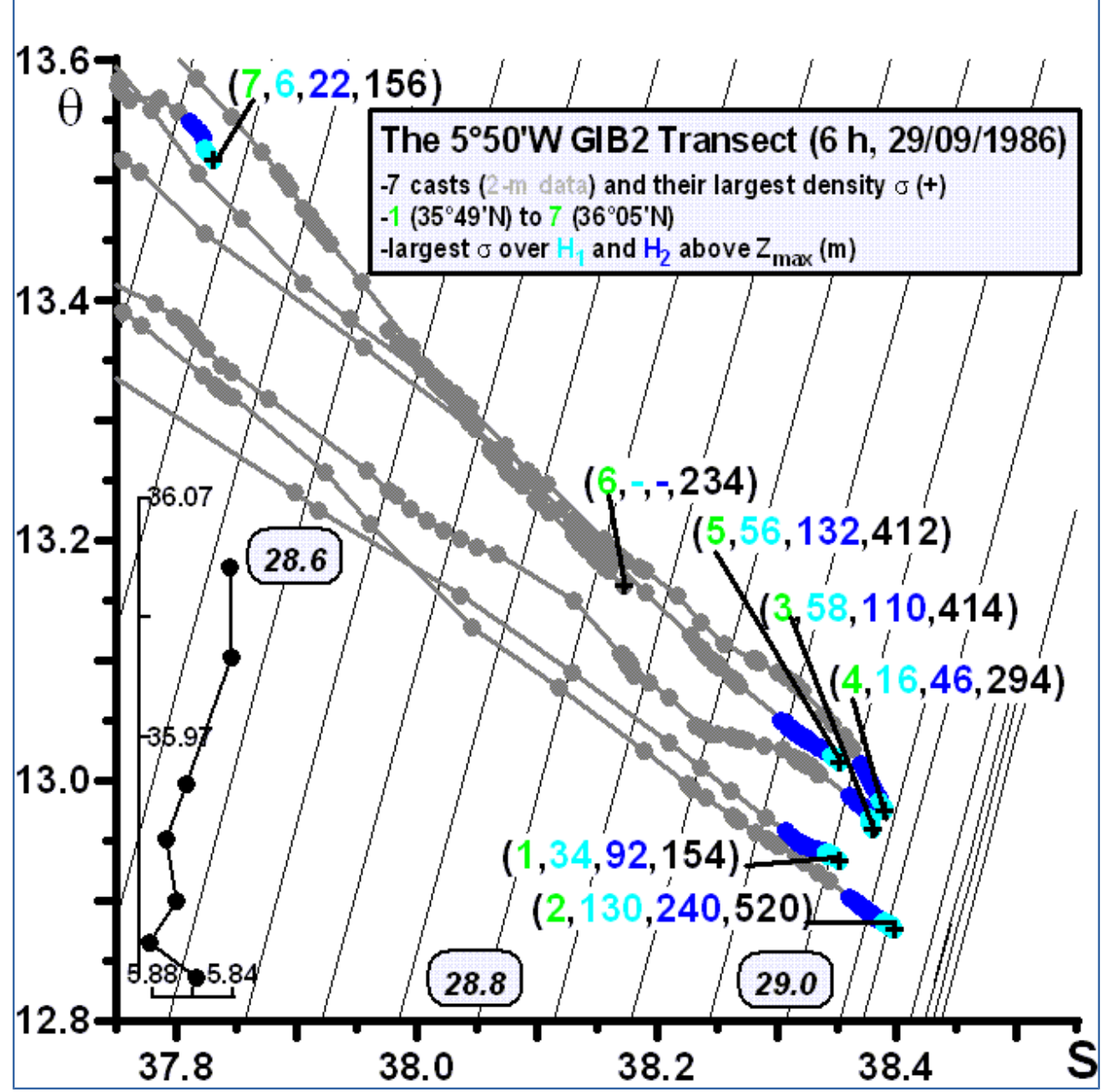

Figure 2g. Same as in Fig.2a for the GIB2 transect at 550'W on 29 Sep. 1986.

This transect was not repeated but it was performed more or less across the whole Strait till $36^{\circ} 05^{\prime} \mathrm{N}$. Over all, two sets of mixing lines indicate a mixing either with the SAW-NACW interface (\#1-2-3) or with the base of the SAW layer (\#4-5-6-7) and two major MWs sampled differently (by \#1-2 and \#3-4-5). Other interesting features are:

i) \#1-2 sampled a very thick (240 m) and very homogeneous, cold, salty and dense MW that, when inferring fits as in Fig. $2 \mathrm{~b}$, should be the densest of the MWs evidenced at $5^{\circ} 43^{\prime} \mathrm{W}$ (WDW). Classically, \#1 ( 150 m) sampled the upper part of this MW while \#2, in the deepest part of the Strait, sampled its lower part and was closer to the core. On \#1-2, this dense MW mixes with the SAW-NACW interface. 
Ocean Sci. Discuss., https://doi.org/10.5194/os-2017-53

Manuscript under review for journal Ocean Sci.

Discussion started: 1 August 2017

(c) Author(s) 2017. CC BY 4.0 License.

515 ii) more to the north, \#3 evidenced another relatively thick $(\sim 110 \mathrm{~m})$ and homogeneous MW that clearly mixed with the SAW-NACW interface too, hence leading to a somehow intermediate mixing line in between those in the south and those in the north. Profiles \#4-5 sampled the same MW that, there, clearly mixed with the base of the SAW layer. This MW had its core close to \#3-4, it was relatively thick at \#5 ( 130 m) and only its top was sampled by \#6.

520 iii) \#7 more to the north $\left(36^{\circ} 05^{\prime} \mathrm{N}\right)$ clearly evidenced, a light $\left(\sigma_{\max } \sim 28.5 \mathrm{~kg} . \mathrm{m}^{-3}\right) \mathrm{MW}$ at a relatively shallow depth $(\sim 160 \mathrm{~m})$.

iv) the fact that \#6 did not evidence any MW layer while \#7 evidenced one might indicate that the MO has started splitting before reaching the eastern side of the Strait. 
Ocean Sci. Discuss., https://doi.org/10.5194/os-2017-53

Manuscript under review for journal Ocean Sci.

Discussion started: 1 August 2017

(C) Author(s) 2017. CC BY 4.0 License.

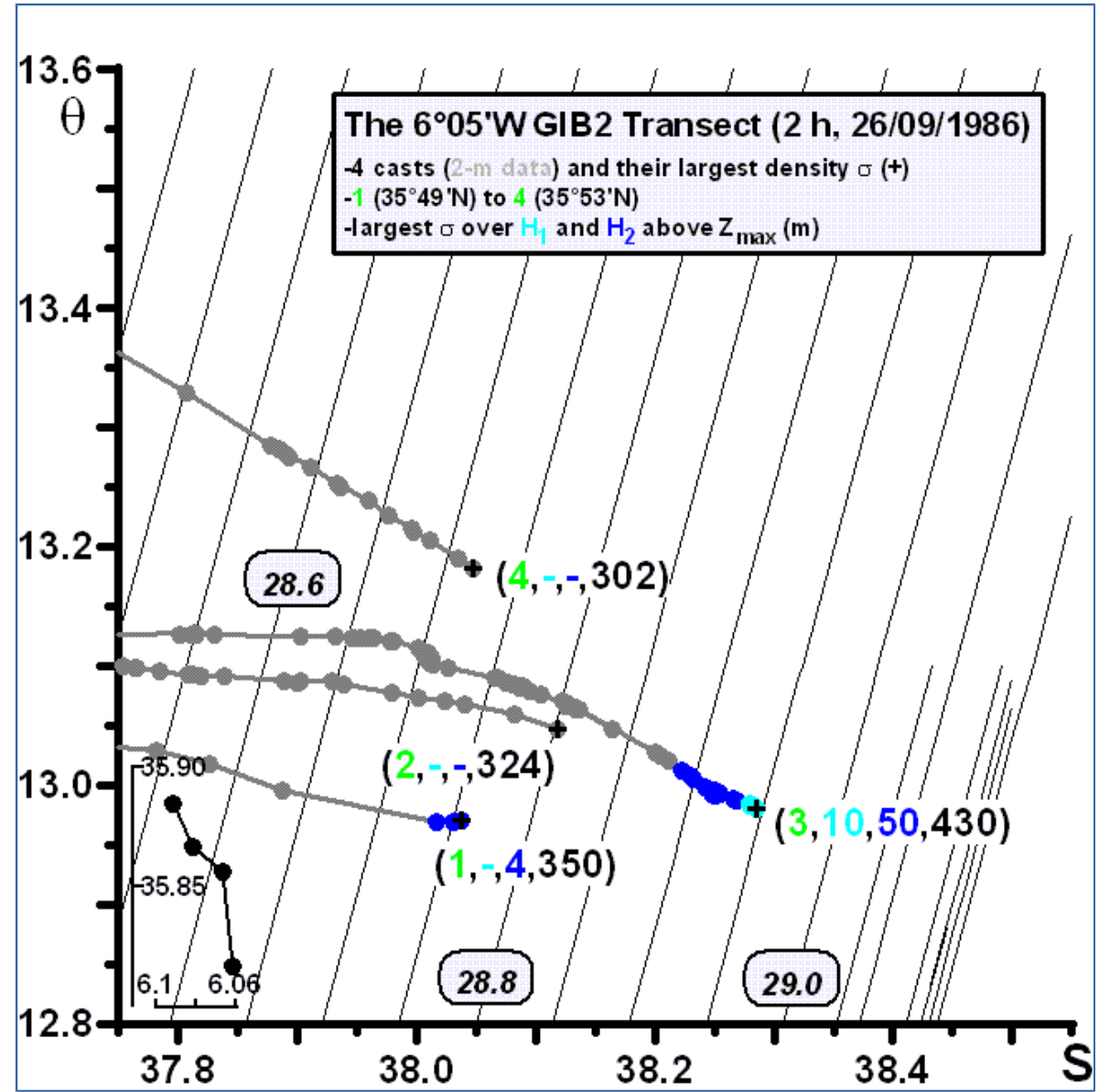

Figure 2h. Same as in Fig.2a for the GIB2 transect at $6^{\circ} 05^{\prime} \mathrm{W}$ on 26 Sep. 1986.

This transect does not have enough profiles across the MO to display very significant features. However, one notes the marked influence of the NACW along the southern continental slope and its north-south spreading: the MO only mixes with NACW in the southern side of the Strait (\#1-2-3) and it clearly mixes with what we called the SAW-NACW interface in its northern side (\#4). Profiles \#1-2 probably sampled the very upper part of the MW only sampled by $\# 3$ over $\sim 50 \mathrm{~m}$. 
Ocean Sci. Discuss., https://doi.org/10.5194/os-2017-53

Manuscript under review for journal Ocean Sci.

(C) Author(s) 2017. CC BY 4.0 License.

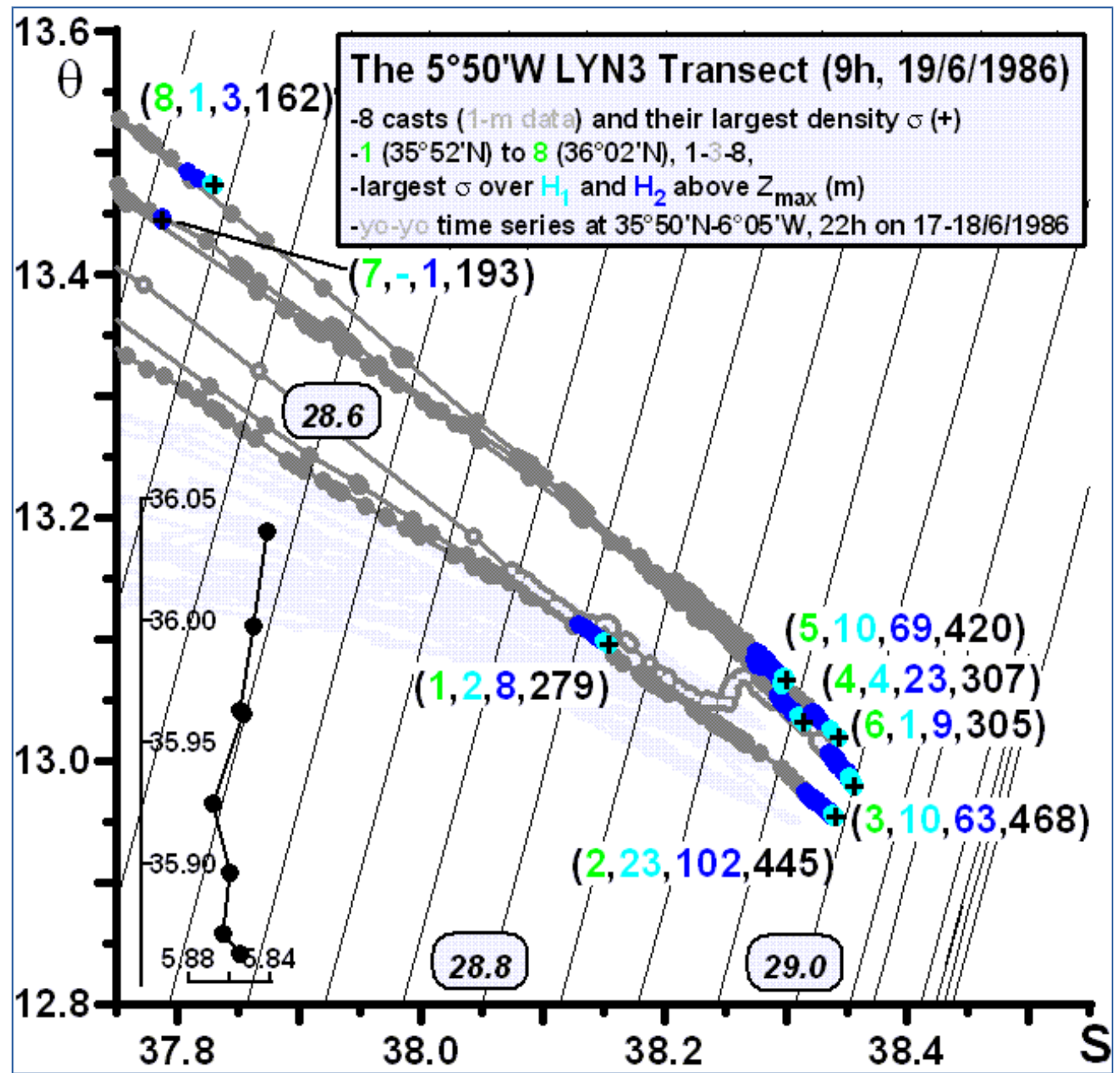

Figure 2i. Same as in Fig.2a for the LYN3 transect at $5^{\circ} 50^{\prime} \mathrm{W}$ on 19 Jun. 1986. Profile \#3 is evidenced by small light gray dots. The yo-yo time series at $6^{\circ} 05^{\prime} \mathrm{W}$ is plotted in light gray.

This transect crosses the whole Strait and efficiently samples the MO. Several interesting features are: i) \#1 is on the upper southern slope where, as usually, only the upper part of the MO is sampled. \#2 is on the lower southern slope and, as usually there, it sampled (even if imperfectly) the densest MW. At both places, the same MW mixes with what we defined as the SAW-NACW interface.

ii) \#3 ( $\left.\sim 35^{\circ} 54^{\prime} \mathrm{N}, \sim 470 \mathrm{~m}\right)$ was nearly as deep as \#2 $\left(\sim 35^{\circ} 52^{\prime} \mathrm{N}, \sim 445 \mathrm{~m}\right)$ but probably on the northern slope since much greater depths were measured in between ( $\sim 35^{\circ} 53^{\prime} \mathrm{N}, \sim 590 \mathrm{~m}$ at $\# 4$ in Fig. $\left.2 \mathrm{~b}\right)$. Profile \#3, and \#4-5-6 as well, sampled a MW that is markedly different from the MW sampled by \#2 and \#1. 
Ocean Sci. Discuss., https://doi.org/10.5194/os-2017-53

Manuscript under review for journal Ocean Sci.

Discussion started: 1 August 2017

(c) Author(s) 2017. CC BY 4.0 License.

iii) in its lower part, the mixing line of $\# 3$ is similar to those of $\# 4-5-6-7-8$, indicating a mixing with the base of the SAW layer, while it is similar to those of \#1-2, indicating a mixing more with the SAW-NACW interface. Definite information is lacking but such a profile can be explained only assuming that the upper part of the MW sampled at \#1-2 has spread northward, up to the position of \#3 only.

iv) while \#7 reached the MO but did not sample any homogeneous layer, \#8 more to the north clearly sampled a light MW (Fig.2i, \#8, $\sigma_{\max }<28.5 \mathrm{~kg} \cdot \mathrm{m}^{-3}$ at $36^{\circ} 02^{\prime} \mathrm{N}$ and $150-160 \mathrm{~m}$ ) in mid 1986. A similarly light MW was sampled there at similar latitude and depth (Fig.2g, \#7, $\sigma_{\max }<28.5 \mathrm{~kg} . \mathrm{m}^{-3}$ at $36^{\circ} 05^{\prime} \mathrm{N}$ and $160 \mathrm{~m}$ ) three months later while what might be another denser MW was sampled more to the south and at greater depths (Fig.2c, \#8, $\left.\sigma_{\max } \sim 28.6 \mathrm{~kg} \cdot \mathrm{m}^{-3}, 35^{\circ} 58^{\prime} \mathrm{N}, \sim 290 \mathrm{~m}\right)$. The characteristics of the lightest MW sampled at $5^{\circ} 50^{\prime} \mathrm{N}$ should be compared with those at $6^{\circ} 05^{\prime} \mathrm{W}$ (Fig. $2 \mathrm{~d}, \# 5, \sigma_{\max } \sim 28.5 \mathrm{~kg} \cdot \mathrm{m}^{-3}, 35^{\circ} 55^{\prime} \mathrm{N}, \sim 320 \mathrm{~m}$ ) in late 1985. Not considering the several-month lag between the observations of the lightest $\left(\sigma_{\max } \sim 28.5 \mathrm{~kg} \cdot \mathrm{m}^{-3}\right) \mathrm{MW}$ at $5^{\circ} 50^{\prime} \mathrm{W}$ and $6^{\circ} 05^{\prime} \mathrm{W}$, hence assuming relatively permanent features, the marked differences in depth (150-160 m vs. $320 \mathrm{~m})$ might reveal a significant sinking of that MW. Such a sinking would be consistent with the processes foreseen by Howe et al. (1974), it could concern the orange MW (WIW) and be associated finally with the Shallow Core (Ambar et al. ,2008), all these features being detailed in the Background Sect.2 of Part 1.

v) at $5^{\circ} 50^{\prime} \mathrm{N}$, this light $\left(\sigma_{\max } \sim 28.5 \mathrm{~kg} \cdot \mathrm{m}^{-3}\right)$ was relatively isolated since when measured at \#8 (Fig.2i) and \#7 (Fig.2g) no MW was clearly sampled at the location more to the south (at \#7 in Fig.2i and \#6 in Fig.2g). If significant, such a feature would indicate a splitting of the lightest component of the MO more or less as soon as the Camarinal sills.

vi) links are obvious with the yo-yo time series collected 1-2 days before at $6^{\circ} 05^{\prime} \mathrm{W}$ (gray in Fig.2i) and analyzed in Sect. 2.2.10 and Sect. 3. 
Ocean Sci. Discuss., https://doi.org/10.5194/os-2017-53

Manuscript under review for journal Ocean Sci.

Discussion started: 1 August 2017

(c) Author(s) 2017. CC BY 4.0 License.

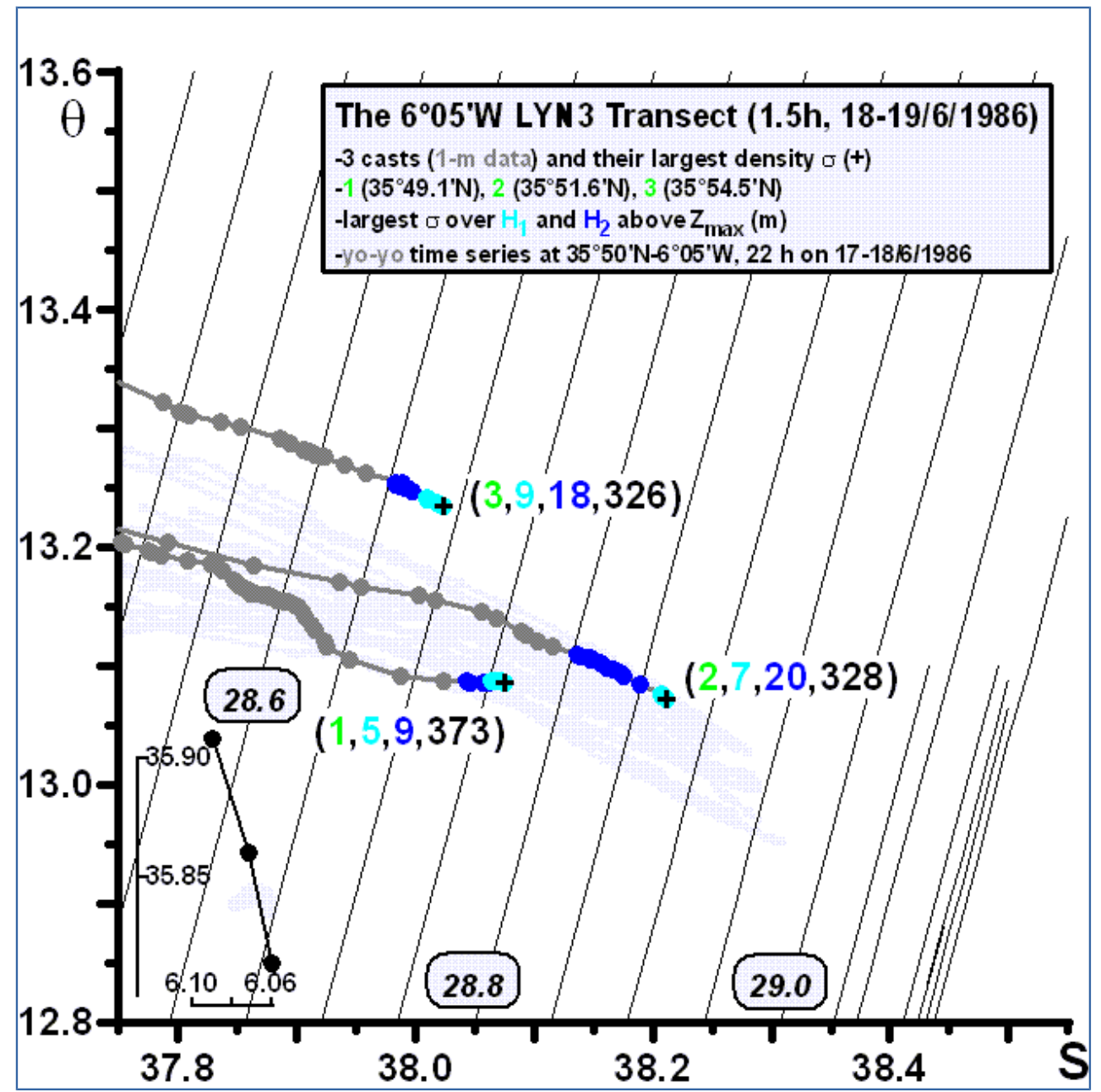

Figure 2j. Same as in Fig.2a for the LYN3 transect at $6^{\circ} 05^{\prime} \mathrm{W}$ on 18-19 Jun. 1986. The yo-yo time series at $6^{\circ} 05^{\prime} \mathrm{W}$ is plotted in light gray.

This Fig.2j first shows the limits of a too coarse sampling as already evidenced by Fig. $2 \mathrm{~h}$ in particular, and it provides the same kind of not very significant and/or already known information. However, it appears to be of marked interest since it allows comparing the yo-yo time series performed on Jun. 17-18 at a location that is just in between \#1 and \#2 performed just after. The MWs more or less simultaneously sampled at locations \#1 and 2 that are 2.5 nautical miles $(\sim 4.5 \mathrm{~km})$ apart have been sampled, in a much more efficient and significant way, at a location in between within a 1-day interval. It might even be that more than two MWs, or types of MWs, are evidenced with such a yo-yo strategy, as definitely demonstrated below. 
Ocean Sci. Discuss., https://doi.org/10.5194/os-2017-53

Manuscript under review for journal Ocean Sci.

Discussion started: 1 August 2017

(c) Author(s) 2017. CC BY 4.0 License.

\section{The MO heterogeneity from the LYN3 yo-yo CTD time series at $35^{\circ} 50^{\prime} \mathrm{N}-6^{\circ} 05^{\prime} \mathrm{W}$}

This yo-yo time series consists in 26 profiles and was performed within $\sim 22 \mathrm{~h}$ on $17-18$ Jun. 1986 during the LYN3 campaign of GIBEX, in the western side of the Strait downstream from the Espartel southern sill (Fig.1a). The lightest $\left(\sigma_{\max } \sim 28.5 \mathrm{~kg} . \mathrm{m}^{-3}\right)$ MW evidenced at $150-160 \mathrm{~m}$ along the upper part of the northern continental slope by the longest transects at $5^{\circ} 50^{\prime} \mathrm{W}$ (Fig.2g, 2i), and that might have markedly deepen, still along the northern continental slope, down to $\sim 320 \mathrm{~m}$ at $6^{\circ} 05^{\prime} \mathrm{W}$ (Fig.2d), but at $35^{\circ} 55^{\prime} \mathrm{N}$ (\#5) there will, most of the time, not be evidenced at such a southward location of $35^{\circ} 50^{\prime} \mathrm{N}$. Now, relatively dense MWs have been observed there, even more to the north, as in Fig. $2 \mathrm{~h}\left(\sigma_{\max } \sim 28.95 \mathrm{~kg} \cdot \mathrm{m}^{-3}, \# 3,35^{\circ} 52 \mathrm{\prime}, 430 \mathrm{~m}\right)$ and Fig. $2 \mathrm{a}\left(\sigma_{\max } \sim 29.0 \mathrm{~kg} \cdot \mathrm{m}^{-3}, \# 4\right.$, $\left.35^{\circ} 50,2^{\prime} \mathrm{N}, 420 \mathrm{~m}\right)$. Note that, $1-2$ days before the time series, Fig. $2 \mathrm{j}$ only evidenced $\sigma_{\max } \sim 28.75 \mathrm{~kg} . \mathrm{m}^{-3} \mathrm{a}$ bit

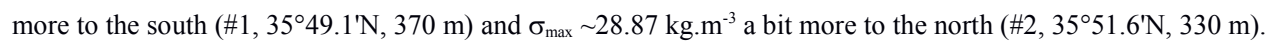
Last but not least, note that no profiles have been performed at $6^{\circ} 05^{\prime} \mathrm{W}$ south of $\sim 35^{\circ} 49^{\prime} \mathrm{N}$ where the depth is still 350-370 m (Fig.2a, 2f, 2g), which does not allow being sure that the densest component of the MO has ever been sampled there.

As we did in Part 1 and will do in Part 3, we performed a detailed analysis of the CTD profiles from the time series at the depth unit $(1-\mathrm{m} / \mathrm{db})$ scale, still with the overall aim to make an analysis as objective as possible.

600 Now, even though the 26 profiles could be visually separated into three groups, according to Fig. $2 \mathrm{j}$ and the figures in Sect. 3.1, we provide in Sect. 3.2 objective arguments that argue for a different and more realistic grouping. In any event, Fig. $2 \mathrm{j}$ demonstrates that nearly all profiles from this time series have evidenced MWs denser than those evidenced by \#1-2 during the transect 1-2 days before and, moreover, that the largest $\sigma_{\max }$ $\sim 28.97 \mathrm{~kg} \cdot \mathrm{m}^{-3}$ are close to the overall maxima $\left(\sigma_{\max } \sim 29.0 \mathrm{~kg} \cdot \mathrm{m}^{-3}\right)$ ever sampled at $6^{\circ} 05^{\prime} \mathrm{W}$. 
Ocean Sci. Discuss., https://doi.org/10.5194/os-2017-53

Manuscript under review for journal Ocean Sci.

Discussion started: 1 August 2017

(c) Author(s) 2017. CC BY 4.0 License.

\subsection{The three groups}

The firstly observed group (\#1 to \#8 represented by \#6, Fig.3a) gathers most of the profiles in the group visually inferred that is associated with intermediate values of all parameters $\left(\theta, S, \sigma_{q}\right)$ in the lowest parts of the profiles, excluding \#14 (see Fig.3c) that evidences a relatively large $\sigma_{\max }$ and has been obtained much later. Note that the sets of extreme values $\left(\theta_{\min }, \mathrm{S}_{\max }, \sigma_{\max }\right)$ are distributed over relatively wide ranges.

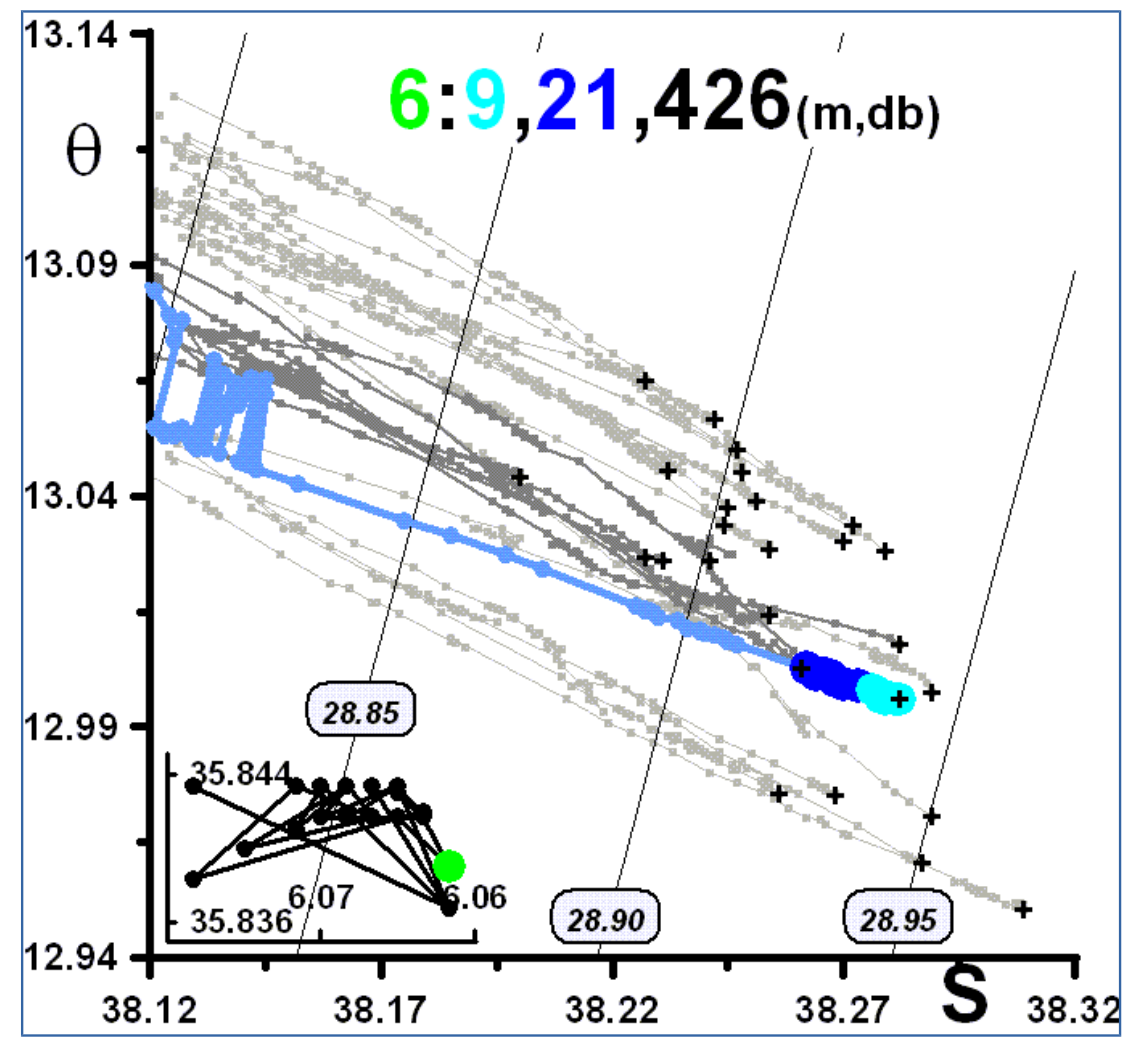


Ocean Sci. Discuss., https://doi.org/10.5194/os-2017-53

Manuscript under review for journal Ocean Sci.

Discussion started: 1 August 2017

(c) Author(s) 2017. CC BY 4.0 License.

645 The secondly observed group, mainly formed by \#9 to \#13 and represented by \#10 (Fig.3b), essentially evidences the coolest values in the lower part of the profiles. Profiles \#11-12-13 are very similar to \#10 over the displayed ranges while \#9 is more similar to \# 6 than to \#10 in the upper part of the profiles so that \#9, the first profile in the second group, could a priori have been included in the first group. In any event, \#9 represents some kind of transition phase between these two first groups, as illustrated (Fig.4b) by a mixing line segmented in an a situation was already encountered during the transects (Fig.2i, \#3) and such a segmentation of the mixing line is also observed for \#14 (see below). Note that the largest $\sigma_{\max } \sim 28.97 \mathrm{~kg} \cdot \mathrm{m}^{-3}$ was evidenced by a profile very different from the profile before (\#9 did not evidence any homogeneous layer, Fig.4b) which, at least, illustrates the difficulty in sampling extreme values.

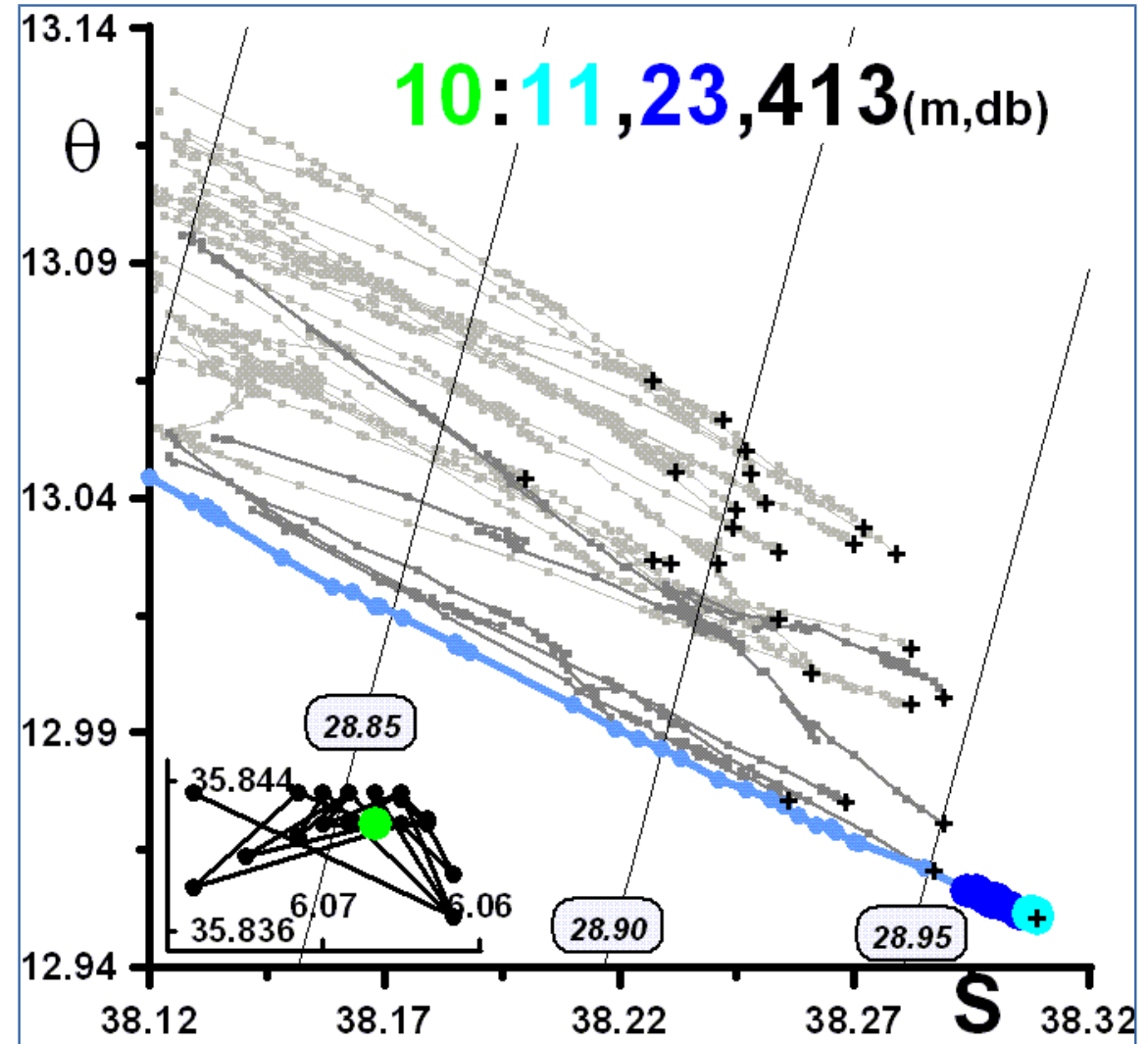

Figure 3b. Same as in Fig.3a for profile \#10 
Ocean Sci. Discuss., https://doi.org/10.5194/os-2017-53

Manuscript under review for journal Ocean Sci.

Discussion started: 1 August 2017

(c) Author(s) 2017. CC BY 4.0 License. of \#9 and \#14, objectively included in the second group (Sect. 3.2) as the first and last profiles of this group, could thus be representative of some kind of transition phase between the groups.

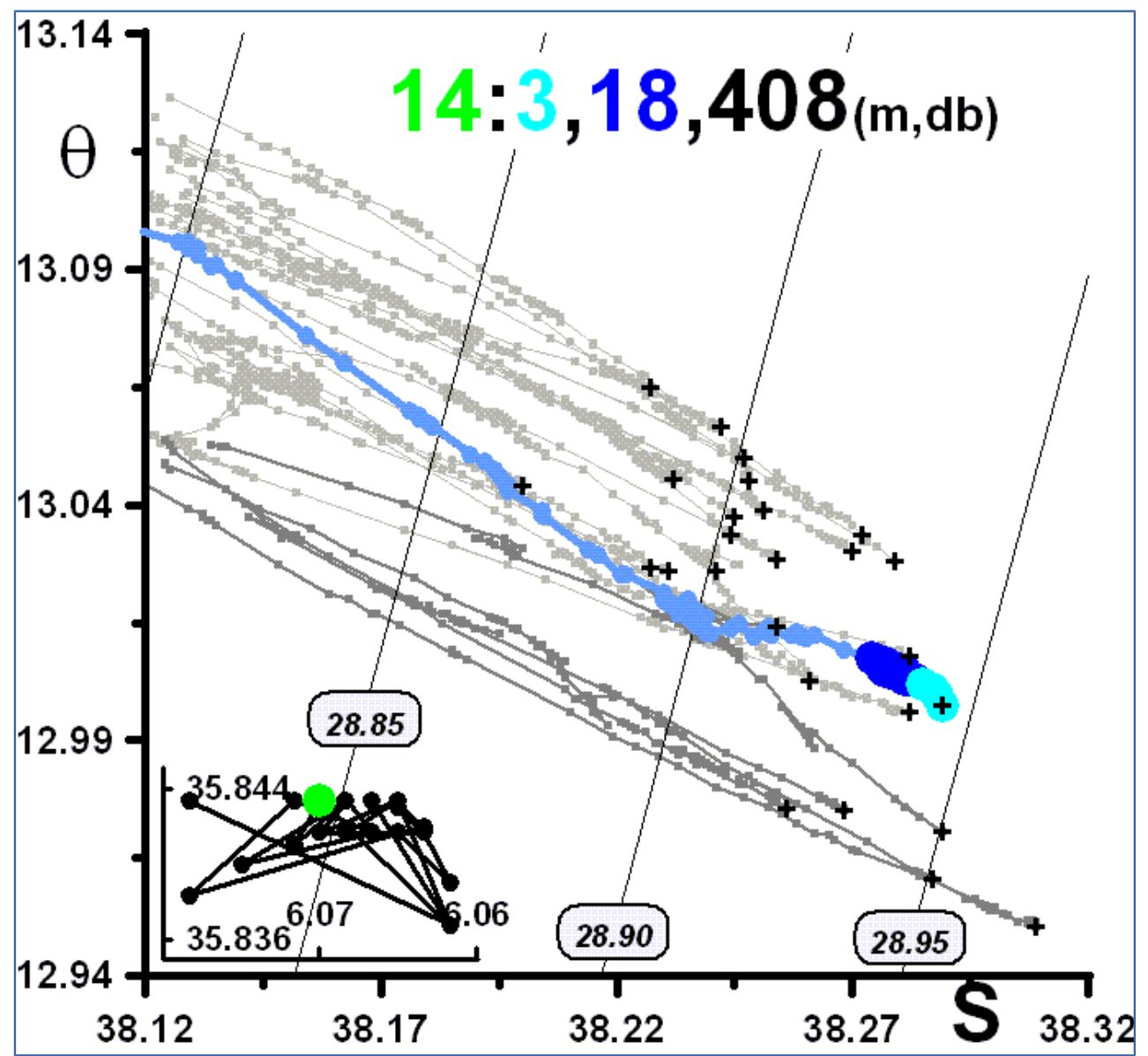

Figure 3c. Same as in Fig.3a for profile \# 14 
Ocean Sci. Discuss., https://doi.org/10.5194/os-2017-53

Manuscript under review for journal Ocean Sci.

Discussion started: 1 August 2017

(c) Author(s) 2017. CC BY 4.0 License.

The third group (\#15 to \#26, represented by \#18, Fig.3d) essentially evidences the warmest values in the lower part of the profiles. Even though it is the most numerous, it also seems to be the most homogeneous, being characterized by $\theta-S-\sigma_{\max }$ sets relatively warm and fresh, hence light. Now, since some profiles (e.g. \#20, Fig.4c) have mixing line slopes markedly different from others, the significance of this homogeneity can be questioned, which will be done in Sect. 3.2.

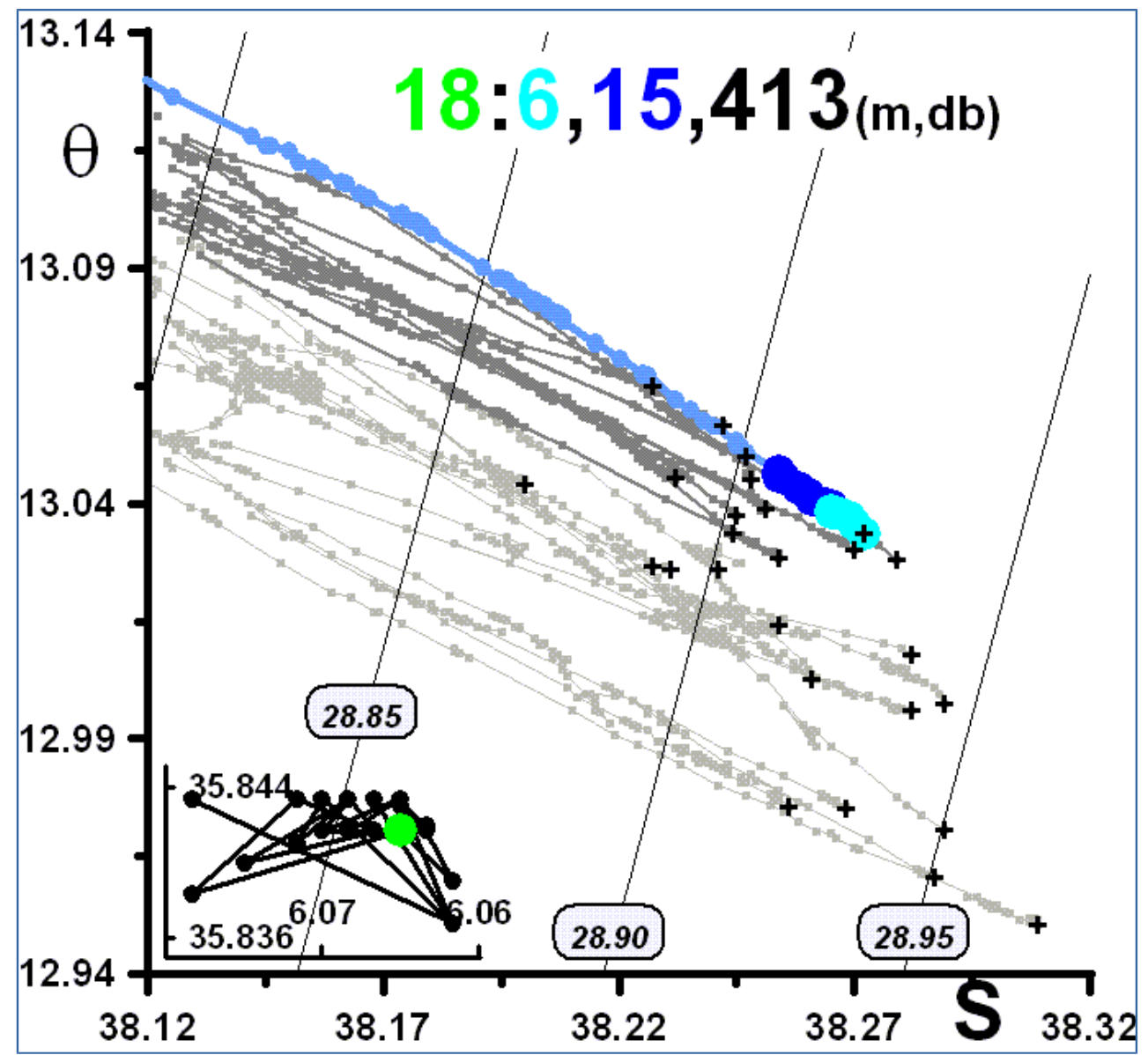

Figure 3d. Same as Fig.3a for profile \# 18

All other profiles are presented as Fig.4a, b, c: 
Ocean Sci. Discuss., https://doi.org/10.5194/os-2017-53

Manuscript under review for journal Ocean Sci.

Discussion started: 1 August 2017

(c) Author(s) 2017. CC BY 4.0 License.

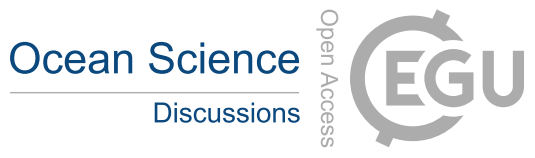

(c) (i)

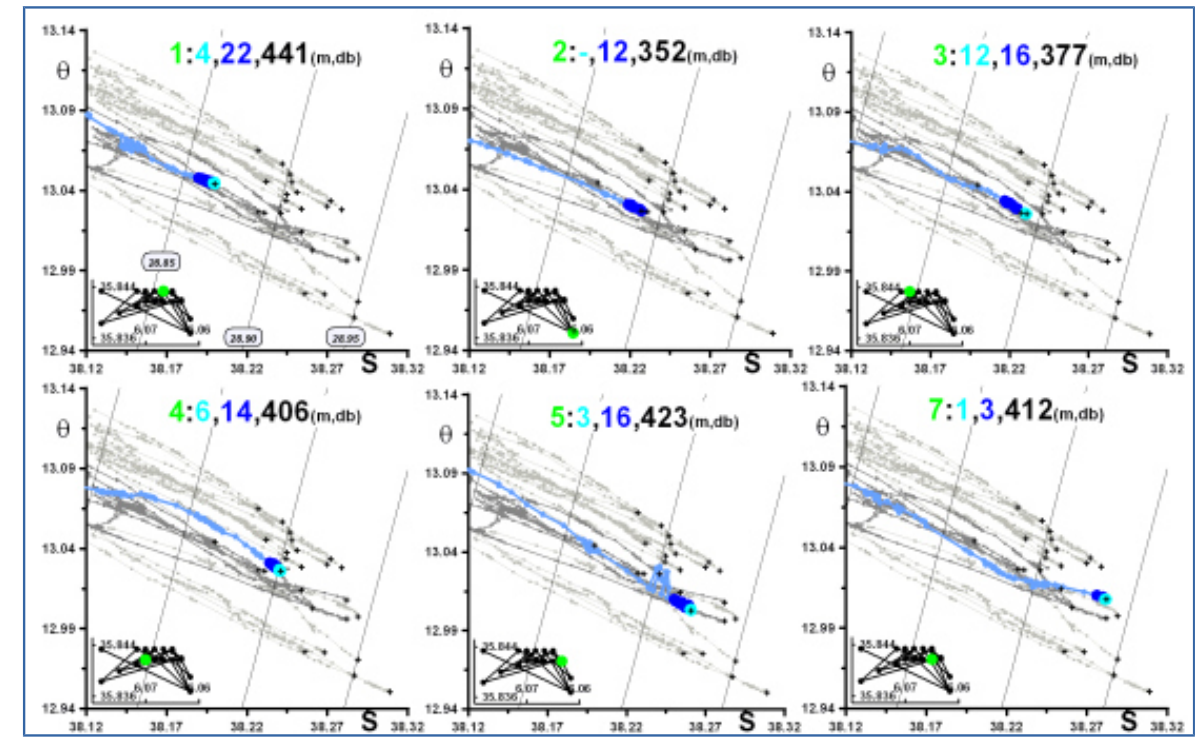

Figure 4a. Same as in Fig.3a for other profiles of the yo-yo time series. 
Ocean Sci. Discuss., https://doi.org/10.5194/os-2017-53

Manuscript under review for journal Ocean Sci.

Discussion started: 1 August 2017

(c) Author(s) 2017. CC BY 4.0 License.

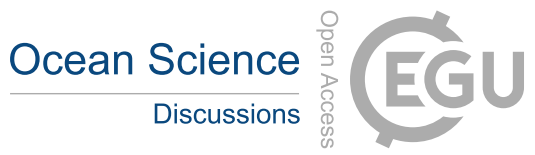

\section{(c) (1)}

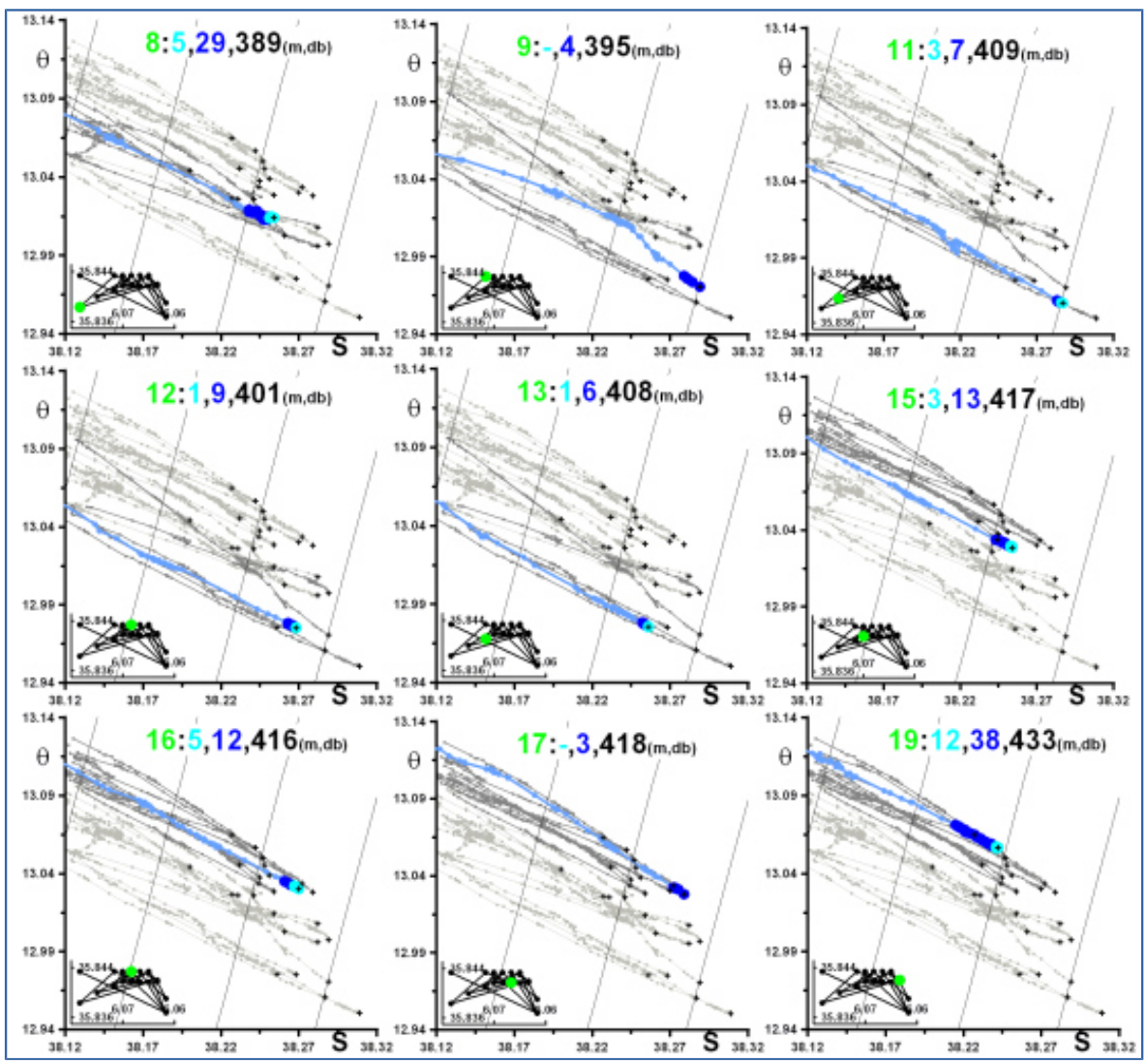

Figure 4b. Same as in Fig.3a for other profiles of the yo-yo time series. 
Ocean Sci. Discuss., https://doi.org/10.5194/os-2017-53

Manuscript under review for journal Ocean Sci.

Discussion started: 1 August 2017
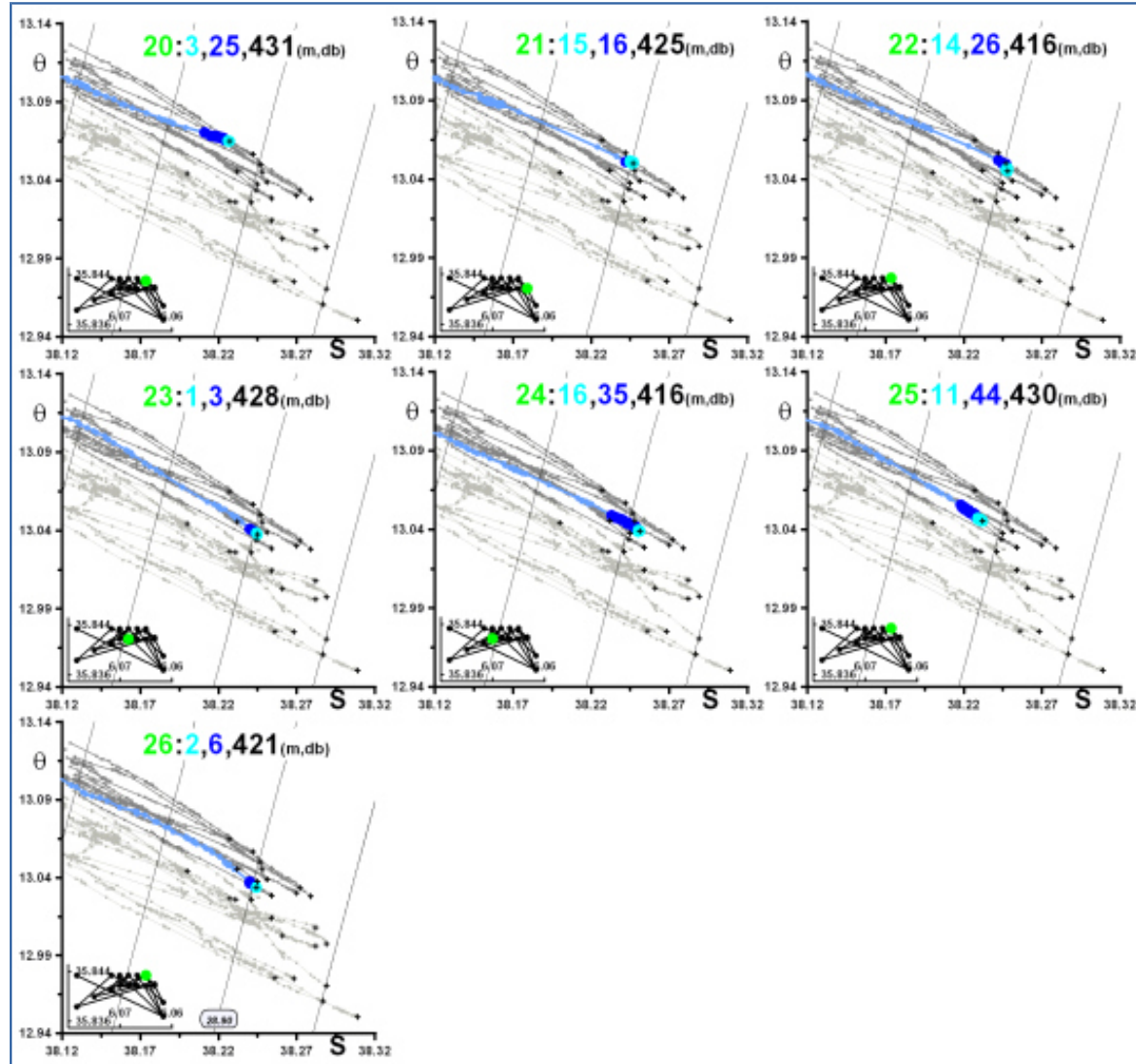

Figure 4c. Same as in Fig.3a for other profiles of the yo-yo time series.

Note from Fig.3,4 that nearly all profiles evidence bottom layers that could be qualified as either very

homogeneous, in cyan being a few $\mathrm{m}$ up to $\sim 15$-m thick, or relatively homogeneous, in blue being a few tens up to 45 - $\mathrm{m}$ thick. Because, at least to our knowledge, the CTD probe was not equipped with an acoustic device that would have allowed sampling close to the bottom, and because the especially difficult conditions in the Strait prevent from fully relying on the ship depth-sounder to infer the altitude of the CTD from the pressure measurements it provides, it should be considered that the thickness of a very/relatively homogeneous MW there was more probably in the order of $20 / 50 \mathrm{~m}$.

The classification into three groups is somehow supported by the plots of $\theta$ (Fig.5a), S (Fig.5b) and $\sigma_{\mathrm{q}}$ (Fig.5c). Differences, in either mean values of the $\theta-S-\sigma_{q}$ sets or in the homogeneity of representative sets, have already been emphasized in Part 1 at the Strait entrance and related to the characteristics of the MWs we associated to each of them. We thus try, in Sect. 3.2, to link the data from the yo-yo time series at $6^{\circ} 05^{\prime} \mathrm{W}$, where identification with the MWs cannot be done for sure, to the data from the yo-yo time series at $5^{\circ} 43^{\prime} \mathrm{W}$ and to the MWs associated there. 
Ocean Sci. Discuss., https://doi.org/10.5194/os-2017-53

Manuscript under review for journal Ocean Sci.

Discussion started: 1 August 2017

(c) Author(s) 2017. CC BY 4.0 License.

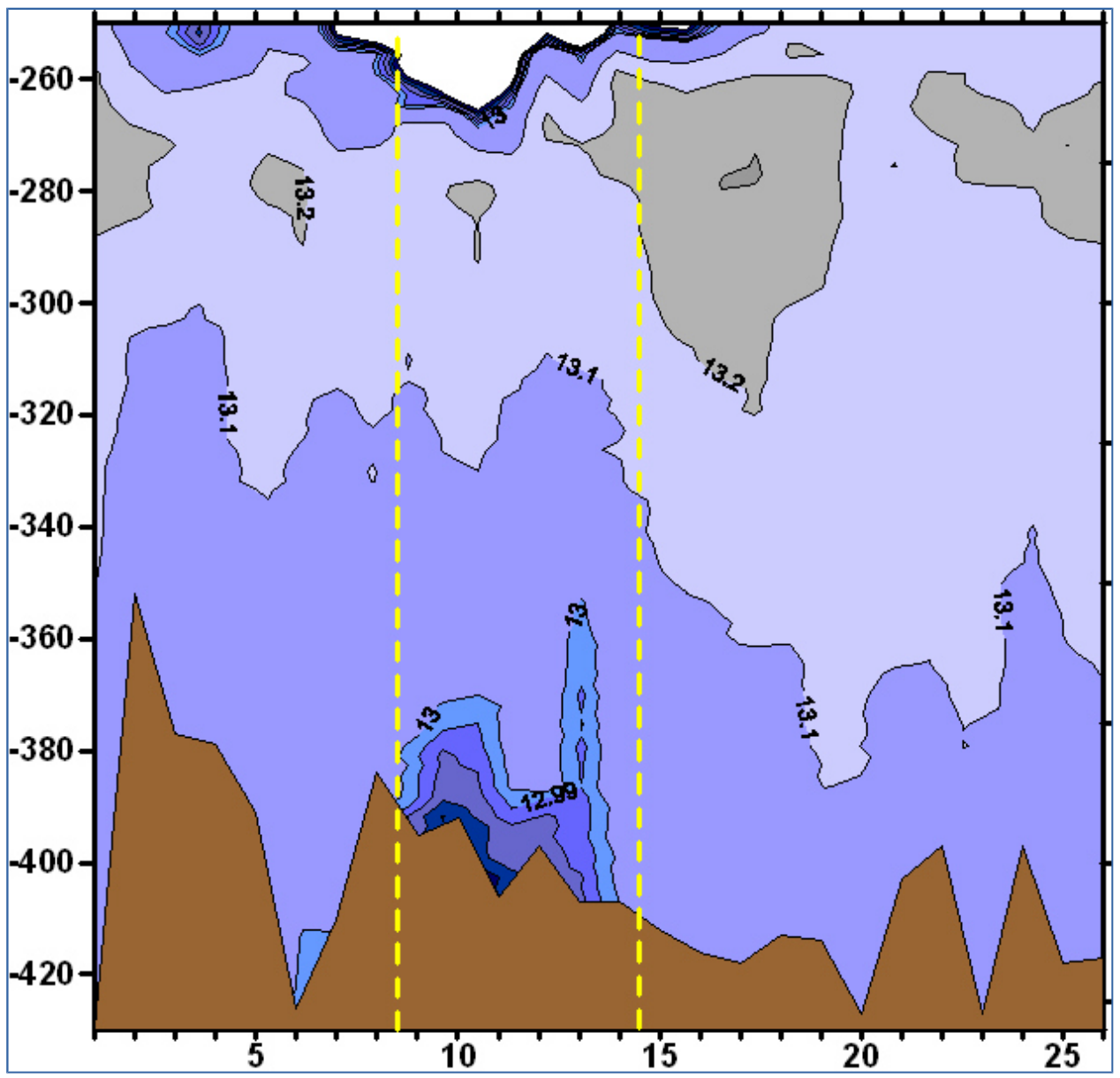

Figure 5a. $\theta(\mathrm{z}, \mathrm{N})$ in ${ }^{\circ} \mathrm{C}$ for the yo-yo time series, with $\mathrm{z}$ from $-250 \mathrm{~m}$ to $-430 \mathrm{~m}$ and $\mathrm{N}$ from 1 to 26 . Dashed yellow lines define the three groups of profiles. 
Ocean Sci. Discuss., https://doi.org/10.5194/os-2017-53

Manuscript under review for journal Ocean Sci.

Discussion started: 1 August 2017

(c) Author(s) 2017. CC BY 4.0 License.

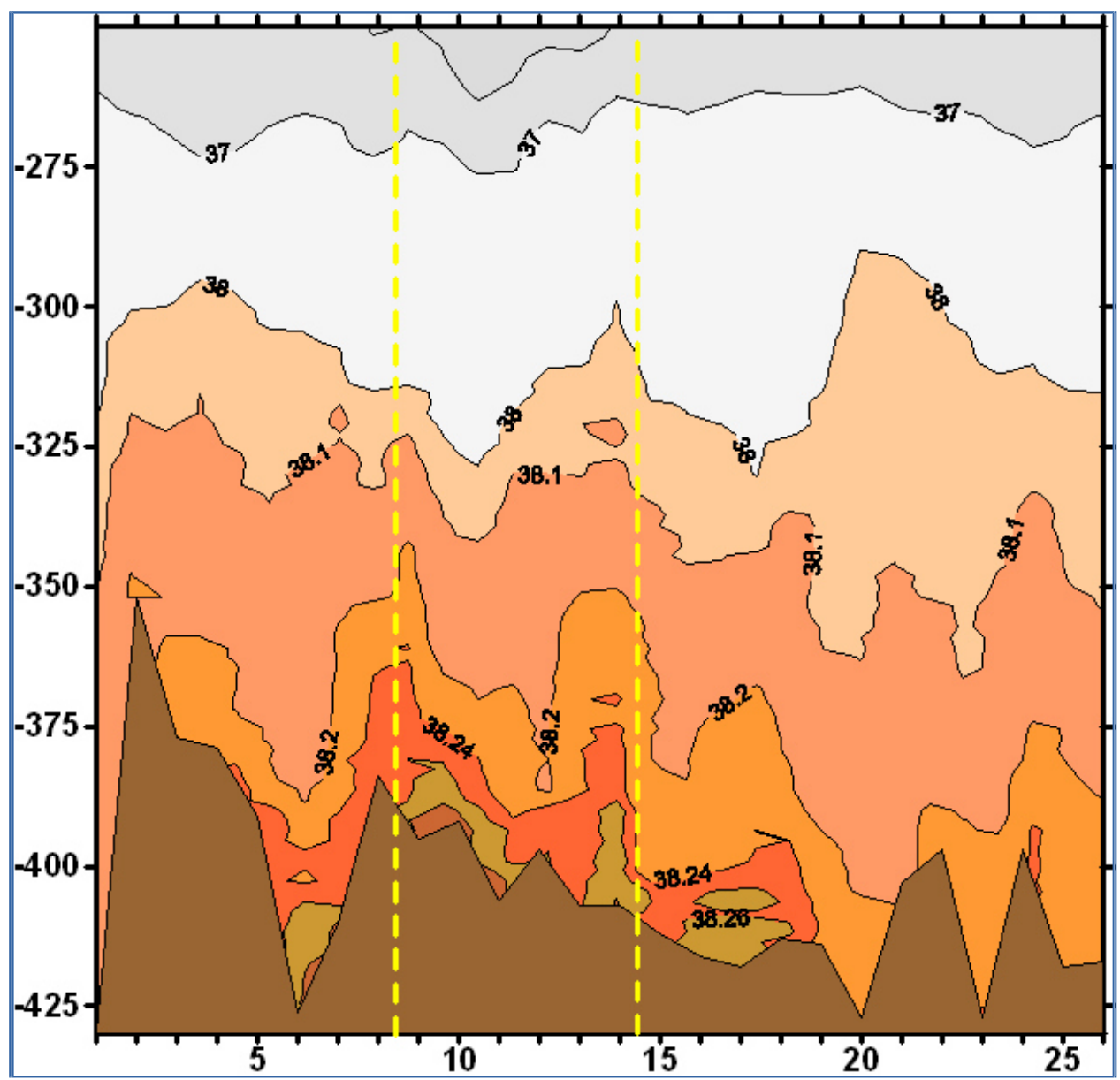

Figure 5b. Same as in Fig.5a for S. 
Ocean Sci. Discuss., https://doi.org/10.5194/os-2017-53

Manuscript under review for journal Ocean Sci.

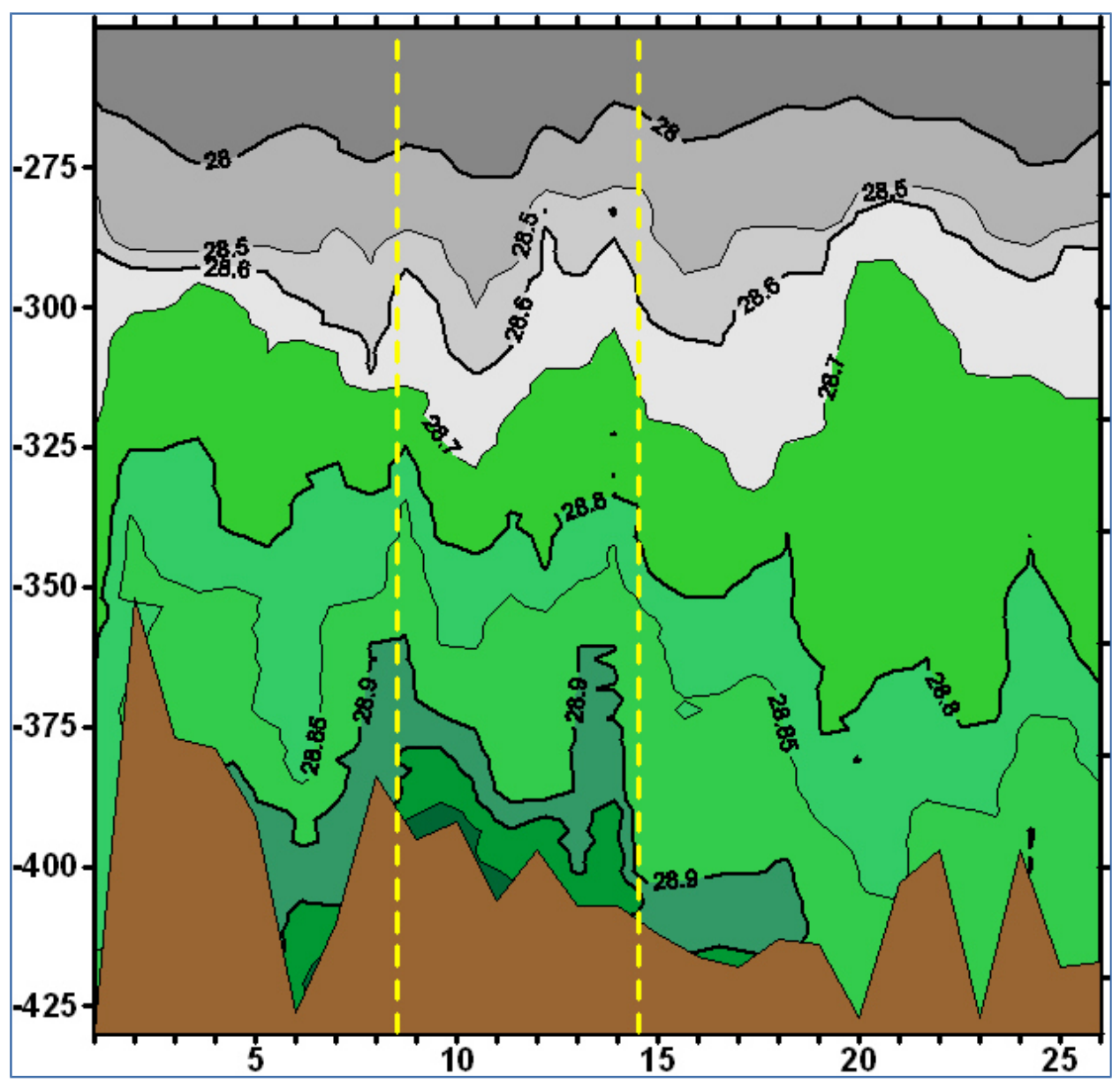

Figure 5c. Same as in Fig.5a for $\sigma_{\mathrm{q}}$ in kg. $\mathrm{m}^{-3}$.

\subsection{An attempt to associate MWs with CTD data at $6^{\circ} 05^{\prime} \mathrm{W}$}

The significance of correlation computations between the Espartel (E) and Camarinal (C) time series from moored CTDs has been demonstrated by Millot (2014a, Fig.26-29). Indeed, after having considered the 8-h time lag inferred from the correlation (which, with a $\sim 20-\mathrm{km}$ separation, corresponds to an average speed from $\mathrm{C}$ to $\mathrm{E}$ of $\sim 0.7 \mathrm{~ms}^{-1}$ ), and after having checked that the slopes of the mixing lines (MLS over time $\mathrm{t}$ ) at both $\mathrm{E}$ and $\mathrm{C}$ were similar, we inferred, at any $t$ and from the set $\mathrm{q}(\mathrm{E})-\mathrm{S}(\mathrm{E})-\mathrm{MLS}(\mathrm{E}, \mathrm{C})-\mathrm{S}(\mathrm{C})$ a $\mathrm{q}_{\text {inferred }}(\mathrm{C})$ that appears to be nearly the actual $\mathrm{q}(\mathrm{C})$. This result led us tempting to identify the MWs observed at $6^{\circ} 05^{\prime} \mathrm{W}$ from the classification we made at $5^{\circ} 43^{\prime} \mathrm{W}$. Considering the variability of the MWs that cannot be neglected during the 
Ocean Sci. Discuss., https://doi.org/10.5194/os-2017-53

Manuscript under review for journal Ocean Sci.

Discussion started: 1 August 2017

Discussions

(C) Author(s) 2017. CC BY 4.0 License.

(c) (i)

long 7-month period between the data sets at $5^{\circ} 43^{\prime} \mathrm{W}$ (7-8 Nov. 1985) and at $6^{\circ} 05^{\prime} \mathrm{W}$ (17-18 Jun. 1986), and the even much larger variability of the AWs that we have illustrated herein, looking for possible relationships between the two data sets cannot a priori provide significant results. But what we did in a fully objective way could provide more significant results with two more simultaneous data sets, as collected during a single experiment, or even be used with a single data set, and thus deserves to be described.

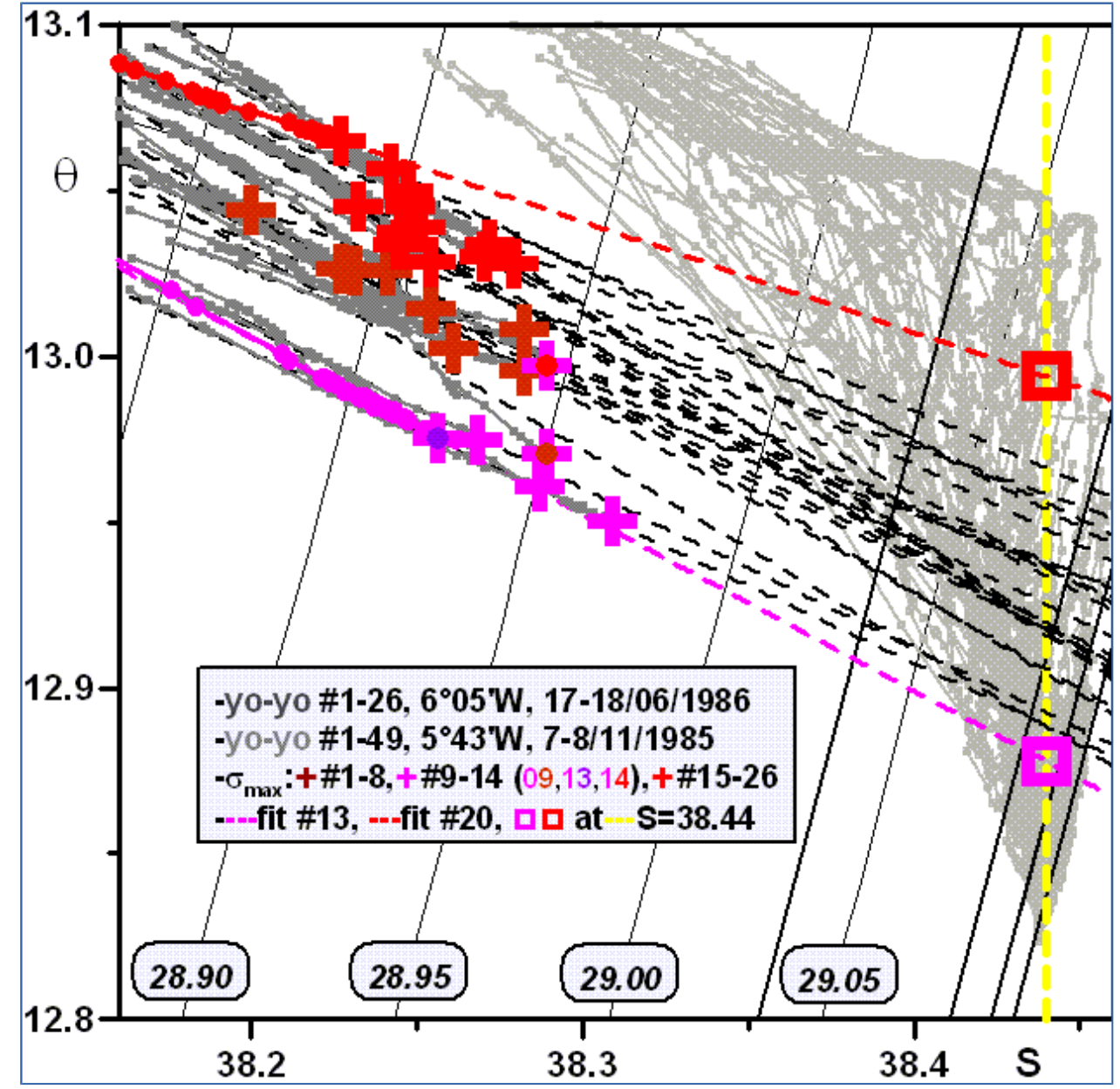

Figure 6a. $\theta$-S diagrams of the 26 profiles of the yo-yo time series at $6^{\circ} 05^{\prime} \mathrm{W}$ (at $35^{\circ} 50^{\prime} \mathrm{N}$ ) on $17-18 \mathrm{Jun} .1986$ in

dark gray together with those of the 49 profiles of the yo-yo time series at $5^{\circ} 43^{\prime} \mathrm{W}$ (at $35^{\circ} 55^{\prime} \mathrm{N}$ ) on 7-8 Nov. 1985 in mild gray. Coloring of the $\sigma_{\max }$ crosses is objectively made according to Fig. $6 \mathrm{~b}$ and the comments in the text. Fits to $\# 13$ (pink) and 20 (red) specify the maximum and minimum $\mathbf{S}_{\theta}$ (and q) inferred for $S=38.44$. 
Ocean Sci. Discuss., https://doi.org/10.5194/os-2017-53

Manuscript under review for journal Ocean Sci.

Discussion started: 1 August 2017

(c) Author(s) 2017. CC BY 4.0 License.

Figure 6a represents together the CTD data from the yo-yo time series at $5^{\circ} 43^{\prime} \mathrm{W}$ and $6^{\circ} 05^{\prime} \mathrm{W}$. We first computed the linear fits associated with the lower parts of all profiles at $6^{\circ} 05^{\prime} \mathrm{W}$ over ranges $\left(12.80-13.10{ }^{\circ} \mathrm{C}, 38.16-38.32\right.$ plotted till 38.46 so as to keep the $\Delta \theta / \Delta \mathrm{S}=1^{\circ} \mathrm{C}$ scale) that are obviously arbitrary but give relatively coherent results, even with the segmented profiles (\#9, \#14); slightly different ranges (we tried $\mathrm{S}_{\min }=38.15$ and 38.12) give slightly different but still coherent results. Fits to all profiles give theoretical $\theta$ and $\sigma_{\mathrm{q}}$ values for the arbitrary chosen $\mathrm{S}=38.44$ that are reasonable within the MWs range and \#13 (resp. \#20) give the coolest-densest (resp. warmest-lightest) set of theoretical data. Obviously, fits over different ranges and a different $\mathrm{S}$ value would have given different theoretical $\mathbf{s}_{\mathrm{q}}$ values, hence different associated colors but, visually, differences cannot be very large. Indeed, fits are relatively parallel, consistently with the whole profiles (in green) shown in Fig.1b; note that a hypothetically homogeneous MO would have given fits converging on the MWs side. In this respect, the mixing with NACW that occurred during the time series is more efficient in identifying the MWs than a mixing that would have occurred with SAW, in particular with the top of that layer (Part 1 and e.g. Fig.1b).

Figure $6 \mathrm{~b}$ shows that the theoretical $\theta$ and $\sigma_{\mathrm{q}}$ time series display characteristics much contrasted than the measured time series. In particular, the theoretical $\sigma_{\mathrm{q}}$ in orange is much contrasted, i.e. it displays more variations, than the measured $\sigma_{\mathrm{q}}$ in blue (these colors have nothing to do with this or that MW). Moreover, the separating isopycnals of 29.08 and $29.09 \mathrm{~kg} \cdot \mathrm{m}^{-3}$ defined in Part 1 clearly allow the identification of three groups from the orange curve at $5^{\circ} 43^{\prime} \mathrm{W}$, which is impossible from the blue curve at $6^{\circ} 05^{\prime} \mathrm{W}$ with any isopycnal; and these groups are roughly those identified visually. Coloring the profiles in a coherent and fully objective way as done in Part 1 leads associating the second group with the pink water, \#13 being slightly violet while \#9 and \#14 are the closest to the red range, consistently with the remarks made above. The first and third group should be red (they are clearly within the $29.035-29.08 \mathrm{~kg} \cdot \mathrm{m}^{-3}$ range) but we colored them differently (in brown and red) since the former is markedly more homogeneous and denser than the latter; note that the characteristics of the groups as observed at $6^{\circ} 05^{\prime} \mathrm{W}$ were either different or less clear.

Whatever the accuracy and significance of such a theoretical coloring and partitioning at a remote location (here $\left.5^{\circ} 43^{\prime} \mathrm{W}\right)$, we thus note that it allows more coherency within each of the groups that any partitioning inferred from local measurements (here $6^{\circ} 05^{\prime} \mathrm{W}$ ). The theoretical groups are not exactly those one would be tempted to infer visually from the data sets but, at least in this case, they are definitely more "realistic" since they are consistent with a variation of the MWs with time: for instance, even if \#14 is relatively different from \#9-13 and apparently similar to \#1-8 (Fig.3,4), associating it to the group \#1-8 would have appeared as some kind of noise in the time series while associating it to the group \#9-13 objectively indicates an actual signal. It is noteworthy that the two segmented profiles (\#9 and \#14) are the first and last of the intermediate group, hence possibly representing transition phases between the three groups. With the hypothesis that this succession of colors is due to a meander of the MO, profile \#13 would indicate the northernmost position of the MO and the red vein would be slightly heterogeneous. 
Ocean Sci. Discuss., https://doi.org/10.5194/os-2017-53

Manuscript under review for journal Ocean Sci.

Discussion started: 1 August 2017

(c) Author(s) 2017. CC BY 4.0 License.

Also note that the theoretical partitioning computed in such a way does not depend dramatically on the penetration of the CTD into the MW layer: be the probe lowered down to the bottom or to some distance from it or even just in the upper part of the MW layer, hence giving very different $\sigma_{\max }$ measurements, the slope of the mixing line, hence the characteristics inferred at an upstream location, will not markedly change and will thus allow identifying the same MW. Obviously, such computations can be applied only to relatively regular profiles displaying a mixing that has been continuous between the sampled MW and a given AW. But such a "method" could also be applied to any individual set of similar data collected in similar conditions by just inferring theoretical values (of e.g. $\mathbf{q}$ and $\mathrm{S}_{\mathrm{q}}$ ) for any arbitrary value (of e.g. S) upstream. 
Ocean Sci. Discuss., https://doi.org/10.5194/os-2017-53

Manuscript under review for journal Ocean Sci.

Discussion started: 1 August 2017

(c) Author(s) 2017. CC BY 4.0 License.

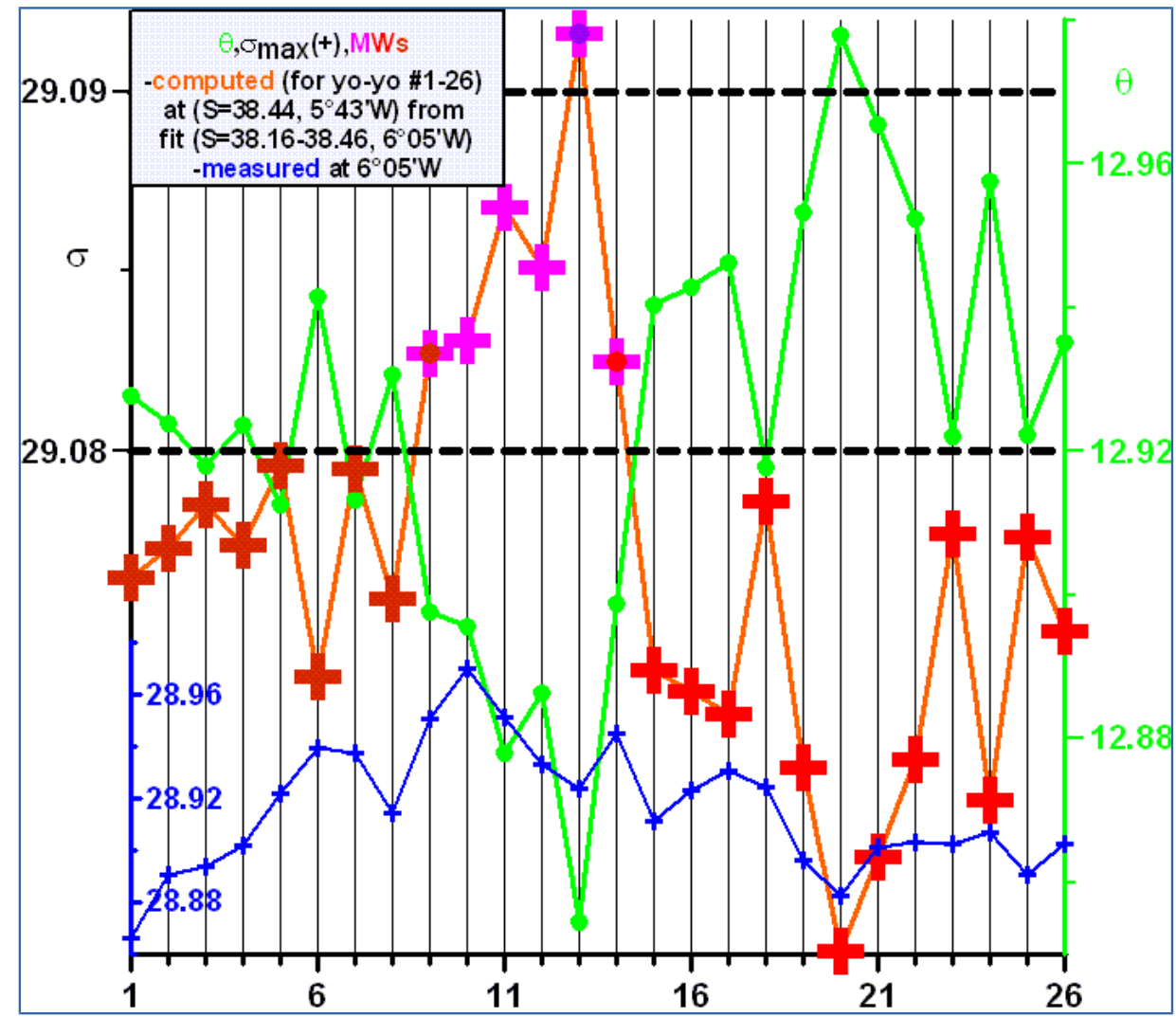

Figure 6b. $\theta$ (green) and $\sigma$ (orange) inferred for $\mathrm{S}=38.44$ from the fits to the 26 profiles at $6^{\circ} 05^{\prime} \mathrm{W}$ (as explained in Fig.6a) for which the measured densities are plotted in blue. Coloring with large crosses is proposed according

to the separation isopycnals inferred in Part 1, as defined with the statistical analysis of the $\sigma_{\max }$ measured at $5^{\circ} 43^{\prime} \mathrm{W}$. The visual grouping of the 26 profiles at $6^{\circ} 05^{\prime} \mathrm{W}$ that can be evidenced by e.g. Fig. 3 and 4 is represented more significantly and coherently by the $\mathrm{S}$ (and q) inferred at $5^{\circ} 43^{\prime} \mathrm{W}$ than by any parameter measured at $6^{\circ} 05^{\prime} \mathrm{W}$. 
Ocean Sci. Discuss., https://doi.org/10.5194/os-2017-53

Manuscript under review for journal Ocean Sci.

Discussion started: 1 August 2017

(c) Author(s) 2017. CC BY 4.0 License.

\section{Discussion}

805

\subsection{The overall density range of the MO}

The very first paper we wrote with a focus on the Strait (Millot et al., 2006) demonstrated, on the basis of moored CTD time series collected at the Camarinal sills since the mid-1990's, that "the densest MWs crossing the Strait have been continuously changing: $\theta$ and S have been markedly increasing, being in the early 2000's much warmer $\left(\sim 0.3{ }^{\circ} \mathrm{C}\right)$ and saltier $(0.06)$ than $\sim 20$ years ago". Linking the GIBEX data collected in the mid 1980's all over the Strait and its surroundings with those collected and analyzed by Ambar et al. (2008) during the MEDTOP cruises conducted essentially in the south of Cape St Vincent in the early 2000's must then be done carefully. Furthermore we cannot presently estimate how these changes in some MWs characteristics modified the MO during its sinking and propagation, along the Iberian continental slope from the Strait to the Cape, we focus herein only on the $\sigma_{q}$ ranges able to characterize the MO at these two locations. We have demonstrated that, even though the GIBEX samplings all over the Strait (at both $5^{\circ} 50^{\prime} \mathrm{W}$ and $6^{\circ} 05^{\prime} \mathrm{W}$ ) were relatively coarse, then certainly underestimating the MO actual $\sigma_{\mathrm{q}}$ range there, ranges of $0.5 \mathrm{~kg} \cdot \mathrm{m}^{-3}$ in both its eastern and western sides were measured during a single transect and validated over time. In Part 3 we analyze more valuable data collected during the MO-2009 experiment at the Strait exit (near $35^{\circ} 45^{\prime} \mathrm{N}-6^{\circ} 20^{\prime} \mathrm{W}$ ) and, show that $\sigma_{\mathrm{q}}$ ranges there are even larger. It is thus obvious that the $\mathrm{MO}$ is horizontally heterogeneous over a range of $0.5 \mathrm{~kg} \cdot \mathrm{m}^{-3}$ at least within the whole Strait, and that such a range alone can account for the range in the veins in the Cape St Vincent surroundings.

\subsection{The long-term hydrological changes and the MO composition}

In Millot et al. (2006), we have started specifying our own understanding of the Strait functioning that we only briefly mentioned previously in our papers dealing with the Sea itself (from Millot (1987) till Millot and TaupierLetage (2005)), depicting in particularity the heterogeneity of the MO linked to the distribution of the MWs we have been expecting from the Strait entrance downstream. And we linked the dramatic changes above described in the characteristics of the densest MWs just over the Camarinal sills to dramatic changes that could have occurred within the Sea. More precisely, and in the light of what was named the Eastern Mediterranean Transient by Roether et al. (1996), which demonstrated that the most efficient zone of dense water formation in the eastern basin had shifted in the early 1990's from the Adriatic sub-basin to the Aegean one, we hypothesized the occurrence of a Mediterranean Sea Transient, that is an eastern basin producing in the early 2000's more dense water (EDW) than the western basin (WDW). We also specified that such a hypothetical Sea Transient could possibly be a direct consequence of the actual eastern basin Transient, hence explaining why only WDW had been recognized at the Strait entrance up to the early 2000's since DW there was mainly (not only) WDW. It is because we realized, in the late 1990's, that all (sic) studies in both the western basin and the Strait never considered the DW formed in the eastern basin that we proposed (Millot, 1999) the TDW acronym, now proposed as EDW. And we clearly specified (Millot et al., 2006) that "the proper functioning of the Sea leads to 
Ocean Sci. Discuss., https://doi.org/10.5194/os-2017-53

Manuscript under review for journal Ocean Sci.

Discussion started: 1 August 2017

(c) Author(s) 2017. CC BY 4.0 License.

a variability of the MO composition that can have consequences for the mid-depth water characteristics in the Ocean much more dramatic than previously thought". We demonstrate in Part 3 that dramatic consequences have actually occurred in the long term within the Strait itself.

845

\subsection{The MO variability within the Strait}

We have started re-analyzing the GIBEX data when focusing on the short-term (10-day) variability of both the AWs and the MWs in the Strait and have described all GIB and LYN transects mentioned herein over the whole $\theta-\mathrm{S}-\sigma_{q}$ ranges (Millot, 2008). We clearly concluded that "specifying any nominal characteristic for the MO all its way downstream, a fortiori any nominal characteristic for the various veins into which it is split, needs monitoring the whole water column within the Strait". We never focused up to now on the GIBEX data at the sampling (1-db or 2-db) level, just considering overall shapes and characteristics of the $\theta-\mathrm{S}$ diagrams. We have now shown (in Part 1, more completely in Part 2) that on nearly all profiles collected within the Strait in the mid 1980 's (as well as in the late 2000's, see Part 3), the characteristics of the various homogeneous layers of MWs found in the lower part of the mixing lines (on $\theta$-S diagrams) clearly demonstrate first the marked heterogeneity of the MO and second the strong dependency of these MWs characteristics on those of the AWs that continuously mix with them. More precisely, a given AW can mix with a given MW at a given place and be replaced, at the same place, by another AW a few days later; in the same way, a given MW can mix with a given $\mathrm{AW}$ at a given place and with another $\mathrm{AW}$ at another place downstream. The marked heterogeneity of the MO is thus necessarily associated with a marked variability of its components' $\theta-S-\sigma_{q}$ characteristics that result not only from the natural variability of the MWs themselves but also from the variability of their interactions with the AWs. Therefore, it will always be a challenge to associate a given $\theta-\mathrm{S}-\sigma_{\mathrm{q}}$ set considered in isolation to this or that MW and it will be always necessary to have an unbiased (quasi-simultaneous) and complete (across the whole Strait) sampling of the MO so as follow and identify the set of four-five components/MWs from the Strait entrance to the Strait exit.

In addition to the consequences for the MO characteristics of a mixing with either NACW only, or SAW only, or even with either the base or the top of the SAW layer that are illustrated in Fig.1b, we have also shown herein that mixing of the MO sometimes occurs with what we have called a NACW-SAW interface layer that would involve AWs located on the relatively permanent NACW-SAW mixing line, in the $13.2-14.0^{\circ} \mathrm{C} \theta$ range. All this AWs variability obviously does not include the interannual variability we evidenced (Millot, 2007) from the 4year time series we collected, within the framework of the HYDROCHANGES program we initiated (CIESM group, 2002), on the southern continental shelf (green dot at $5^{\circ} 43.5^{\prime} \mathrm{W}$ in Fig.1a). This time series from a moored yearly trend dozens times larger than the MWs decadal one, be the latter due to the Nile damming (Rholing and Bryden, 1992) or to local climatic changes (Béthoux et al., 1990). The $\sim 0.2$ overall salinification being associated with a $\sim 0.12 \mathrm{~kg} . \mathrm{m}^{-3}$ densification, reliable data analyzes and numerical simulations dealing with the 
Ocean Sci. Discuss., https://doi.org/10.5194/os-2017-53

Manuscript under review for journal Ocean Sci.

Discussion started: 1 August 2017

(c) Author(s) 2017. CC BY 4.0 License.

Sea functioning must definitively consider the interannual variability of the Mediterranean Inflow" (we propose

Moreover, in addition to such an interannual variability, the time series displayed in Millot (2007, Fig.3) also evidences a marked and relatively unexpected, or at least never accurately quantified up to now, S seasonal variability: at $80 \mathrm{~m}$ on the southern continental shelf (Fig.1a), S display an annual range of $\sim 0.4$ with a maximum in winter and a minimum in summer. Another aspect of the seasonal variability within the Strait has been evidenced (Millot and Garcia-Lafuente, 2011) from correlation computations between the 2004-2008 HYDROCHANGES time series at the Espartel and Camarinal southern sills (Fig.1a). These CTDs, moored at convenient places (relatively flat bathymetry to facilitate the re-deployment after servicing) in order to monitor the MO characteristics in these major passages (only the lightest and minor part of the MO transiting over the northern sills), hence set at relatively different depths ( $\sim 270 \mathrm{~m}$ at Camarinal and $\sim 360 \mathrm{~m}$ at Espartel), appear to be on relatively similar current lines. One major result has been to show that, at both places, the slope (over time and as recorded at a fixed location) of the AWs-MWs mixing lines are, most of the time, roughly the same. This allowed us to clearly demonstrate that the MWs mix mainly with SAW in winter and with NACW in summer, probably as a consequence of the seasonal stratification and SAW-NACW mixing. We concluded that "The MWs mix with AWs that are cooler (warmer) and fresher (saltier) in summer (winter) and the shallower the MWs the shallower the AWs they preferentially mix with. This can be due either to the seasonal stratification of the AWs that would prevent (increase) in summer (winter) mixing between SAW and NACW assumed to occur in relatively stable proportions on a yearly time scale, or to a NACW amount that would be larger in summer."

\section{Conclusion}

The 1985-1986 Gibraltar Experiment (GIBEX) data set that we started re-analyzing in the mid-2000's has an exceptionally high value and should be used to perform additional (and/or verification) analyzes, furthermore it is easily available (MEDAR group, 2002). We have analyzed herein five cross-Strait transects at both $5^{\circ} 50^{\prime} \mathrm{W}$ and $6^{\circ} 05^{\prime} \mathrm{W}$, hence in the eastern and western sides of the Strait, with the aim to support what we demonstrated with only one transect at $6^{\circ} 05^{\prime} \mathrm{W}$ in Part 1 . First, we have demonstrated that the Mediterranean Outflow (MO) is heterogeneous all along the Strait itself, and we have provided numerous examples of this heterogeneity. CTD profiles there evidence only one MW at a time, the densest (resp. lightest) MWs being in the southern (resp. northern) side of the Strait, so that all MWs clearly outflow along the Strait on the bottom as veins being juxtaposed side by side, as we have always been expecting. Repeating the profiles has shown that, at a given place, MWs were markedly changing at an hourly time scale indicating a significant meandering of the MO. Now, vertical profiles will never allow an accurate specification of the MO characteristics there, what could be done within just a few hours by towing a single CTD at some tens of $\mathrm{m}$ above the bottom, once across the Strait.

At the Strait entrance (Part 1), and in a relatively easy way because the vertical sampling was adapted to the vertical layering there, CTD profiles have allowed evidencing four-five superimposed Mediterranean Waters 
Ocean Sci. Discuss., https://doi.org/10.5194/os-2017-53

Manuscript under review for journal Ocean Sci.

Discussion started: 1 August 2017

(c) Author(s) 2017. CC BY 4.0 License.

(MWs) objectively separated by isopycnals spread over $0.06 \mathrm{~kg} \cdot \mathrm{m}^{-3}$, but considering a $\sigma_{\min } \sim 29.0 \mathrm{~kg} \cdot \mathrm{m}^{-3}$ (WIW) and the $S_{\max }=29.0975 \mathrm{~kg} . \mathrm{m}^{-3}$ (WDW) leads to a maximum range of $\sim 0.10 \mathrm{~kg} \cdot \mathrm{m}^{-3}$ for the MWs there. Within the Strait, a $\sigma_{\min } \sim 28.5 \mathrm{~kg} . \mathrm{m}^{-3}$ was sampled twice during the only two convenient (north enough) transects at $5^{\circ} 50^{\prime} \mathrm{W}$ and only once (among five not north enough transects) at $6^{\circ} 05^{\prime} \mathrm{W}$, in both places from relatively isolated profiles, which could represent a significant value for the northernmost component. On the contrary, the relatively large variability of the q-S diagrams in the southern side of the Strait, together with the coarse and inadequate sampling, indicate that $\mathbf{S}_{\max } \sim 29.05 \mathrm{~kg} \cdot \mathrm{m}^{-3}$ (at $5^{\circ} 50^{\prime} \mathrm{W}$ ) and $\mathbf{S}_{\max } \sim 29.0 \mathrm{~kg} \cdot \mathrm{m}^{-3}$ (at $6^{\circ} 05^{\prime} \mathrm{W}$ ) underestimate the $\mathbf{S}_{\max }$ value of the southernmost component. Therefore, $\sigma_{\mathrm{q}}$ decreases between the Strait entrance and the western side of the Strait of $\sim 0.5 \mathrm{~kg} \cdot \mathrm{m}^{-3}$ in the north and $<0.1 \mathrm{~kg} \cdot \mathrm{m}^{-3}$ in the south lead to a MO having at $6^{\circ} 05^{\prime} \mathrm{W}$ an overall range $\mathrm{D} \sigma_{\mathrm{q}}>0.5 \mathrm{~kg} \cdot \mathrm{m}^{-3}$.

This quantifies the description of Baringer and Price (1997a) that, at the Strait exit, the MO is "very asymmetric", but dealing with "some asymmetry of some unique MO" is not an adequate description: the very large differences between nearby profiles shown herein, clearly indicate that the MO is composed of components juxtaposed side by side. This $D \sigma_{\mathrm{q}}>0.5 \mathrm{~kg} \cdot \mathrm{m}^{-3}$ at $\sim 6^{\circ} 05^{\prime} \mathrm{W}$ in the mid 1980 's compares pretty well with the $\mathrm{D} \sigma_{\mathrm{q}}$ $\sim 0.55 \mathrm{~kg} . \mathrm{m}^{-3}$ at $\sim 8^{\circ} 30^{\prime} \mathrm{W}$ in the early $2000^{\prime}$ 's (Ambar et al., 2008), which does not confer to the Strait exit $\left(\sim 6^{\circ} 20^{\prime} \mathrm{W}\right)$, and hypothetical bathymetric effects there, a major role in the splitting. Note that the $\sigma_{\min } \sim 28.5 \mathrm{~kg} . \mathrm{m}$ ${ }^{3}$ values were found at $150-200 \mathrm{~m}$ at $5^{\circ} 50^{\prime} \mathrm{W}$ and $\sim 320 \mathrm{~m}$ at $6^{\circ} 05^{\prime} \mathrm{W}$, which could account for the splitting of the lightest MO component as soon as Camarinal sills and its sinking all along the Strait. Now, and even though such $D \sigma_{q}$ are expected to be relatively permanent features, we show in Part 3 that the MO structure has dramatically changed between the mid-1980's and the late 2000's at the Strait exit $\left(\sim 6^{\circ} 15^{\prime} \mathrm{W}\right)$ and that $D \sigma_{\mathrm{q}}$ there were significantly larger in the late 2000 's.

We have analyzed, for the first time to our knowledge, a CTD yo-yo time series collected in mid-Jun. 1986 at $6^{\circ} 05^{\prime} \mathrm{W}-35^{\circ} 50^{\prime} \mathrm{N}$, just in-between two profiles from a transect performed 1-2 days ago, that illustrates the tremendous interest of such yo-yo time series since several MWs have been clearly passing by within $\sim 22 \mathrm{~h}$, which demonstrates the marked meandering of the MO there. So as to try specifying which MWs have been sampled, we use one of our previous results about the significance of mixing lines (over $\mathrm{z}$ from a profile or over $\mathrm{t}$ from a time series) to look for possible relationships with the MWs clearly evidenced at the Strait entrance $\left(5^{\circ} 43^{\prime} \mathrm{W}\right) \sim 7$ months ago. Due to such a delay, our analysis cannot be conclusive, but it could clearly have been conclusive with quasi simultaneous data sets; indeed, straight mixing lines essentially allow avoiding the differences that can result from different penetrations of the CTD trough a relatively heterogeneous MW, and they seemingly have allowed demonstrating that profiles having some specific irregularities could in fact reveal transition layers between different MWs.

As demonstrated in both Part 1 and Part 2 (and Part 3 as well), yo-yo CTD time series appear to be an efficient sampling strategy, even if during 1-day periods only, provide one has a correct understanding of the general hydrodynamical conditions in a given studied area. With such an understanding in mind, a strategy based on 
Ocean Sci. Discuss., https://doi.org/10.5194/os-2017-53

Manuscript under review for journal Ocean Sci.

Discussion started: 1 August 2017

(c) Author(s) 2017. CC BY 4.0 License.

classical CTD transects, as the GIBEX ones at $5^{\circ} 40^{\prime} \mathrm{W}$ (Part 1), $5^{\circ} 50^{\prime} \mathrm{W}$ and $6^{\circ} 05^{\prime} \mathrm{W}$ (Part 2), is of limited interest since profiles are collected at space and time scales too large there to get a really unbiased information on the horizontal and extrema are never sampled for sure. This strategy has been improved during the MO-2009 experiment (Part 3) with tow-yo CTD cross-Strait and along-Strait transects; but we will demonstrate that such an interval is still too large in the Strait domain. Because the time series at $6^{\circ} 05^{\prime} \mathrm{W}$ has shown that profiles continuously evolve locally, an ideal strategy involving classical instruments can be proposed to definitively specify the MO heterogeneity and meandering there. It consists in using a tow-yo CTD equipped with i) a pinger to sample as close to the bottom as possible or at any given distance from it, ii) a LADCP (Lowered ADCP) or at least a Ship-borne ADCP, iii) ideally, an acoustic device allowing (with the ship's GPS positions) the exact positioning of the CTD. With such an equipment, it should be easy to perform and repeat two kinds of crossStrait transects between the southern and northern 100-m isobaths ( $\sim 50 \mathrm{~km}$ apart near $\left.6^{\circ} 05^{\prime} \mathrm{W}\right)$ : one (forth) with the CTD at 10-20 m over the bottom and a second (back) rising and lowering the CTD across the MO with a sampling interval as short as a few $100 \mathrm{~s} \mathrm{~m}$, ship maneuverability permitting. Just a single CTD transect at 10-20 $\mathrm{m}$ over the bottom will provide more information than all data sets available up to now.

Data availability. Free and easy access of the GIBEX data to everybody via the four MEDAR/MEDATLAS CD's. HYDROCHANGE data available upon request.

Team list. C. Millot is retired and works alone.

Competing Interests. The author declares he has no conflict of interest.

Acknowledgments. This research did not receive any specific grant from funding agencies in the public, commercial, or not-for-profit sectors.

\section{References}

Ambar, I., Serra, N., Neves, F., and Ferreira, T.: Observations of the Mediterranean Undercurrent and eddies in the Gulf of Cadiz during 2001. J. Mar. Sys., 71, 195-220, doi:10.1016/j.jmarsys.2007.07.003, 2008.

Baringer, M., and Price, J.: Mixing and spreading of the Mediterranean Outflow. J. Phys. Oceanogr. 27, 1654-

1677, 1997a.

Baringer, M., and Price, J.: Momentum and energy balance of the Mediterranean Outflow. J. Phys. Oceanogr., 27, 1678-1692, $1997 \mathrm{~b}$.

Béthoux, J. P., Gentili, B., Raunet, J., and Tailliez, D.: Warming trend in the western Mediterranean deep water, Nature, 347, 660-662, 1990.

990 CIESM group: Mediterranean Water Masses acronyms. Round table session of the $36^{\text {th }}$ CIESM Congress, Monte Carlo. http://www.ciesm.org/catalog/WaterMassAcronyms.pdf, 2001.

CIESM group: Tracking long term hydrological change in the Mediterranean Sea. Workshop Series $n^{\circ} 16$ edited by C. Millot and F. Briand, 134 p, 2002. 
Ocean Sci. Discuss., https://doi.org/10.5194/os-2017-53

Manuscript under review for journal Ocean Sci.

Discussion started: 1 August 2017

(c) Author(s) 2017. CC BY 4.0 License.

García-Lafuente, J., Sánchez-Román, A., Naranjo, C., and Sánchez-Garrido, J.C.: The very first transformation

of the Mediterranean outflow in the Strait of Gibraltar. J. Geophys. Res., 116(C7), C07010.

http://dx.doi.org/10.1029/2011JC006967, 2011.

Garcia-Lafuente, J., Naranjo, C., Sammartino, S., Sanchez-Garrido, J., and Delgado, J.: The Mediterranean

outflow in the Strait of Gibraltar and its connection with upstream conditions in the Alboran Sea, Ocean Sci., 13, 195-207. doi:10.5194/os-13-195-2017, 2017.

Howe, M., Abdullah, M., and Deetea, S.: An interpretation of the double T-S maxima in the Mediterranean outflow using chemical tracers. J. Mar. Res., 32, 3, 377-383, 1974.

MEDAR group: MEDATLAS/2002 database. Mediterranean and Black Sea database of temperature salinity and bio-chemical parameters. Climatological Atlas. IFREMER Edition (4 CDroms), 2002.

Millot, C.: Circulation in the Western Mediterranean Sea. Oceanol. Acta, 10, 2, 143-149, 1987.

1005 Millot, C.: Circulation in the Western Mediterranean Sea. J. Mar. Systems, 20, 1-4, 423-442, 1999.

Millot, C.: Interannual salinification of the Mediterranean inflow. Geophysical Research Letters, 34, L21069, doi:10.1029/2007/GL031179, 2007.

Millot, C.: Another description of the Mediterranean Sea outflow. Progr. Oceanogr., vol. 82, iss. 2, 101-124. doi:10.1016/j.pocean.2009.04.016, 2009.

1010 Millot, C.: Levantine Intermediate Water characteristics: an astounding general misunderstanding! Scientia Marina 77(2), 217-232. doi:10.3989/scimar.03518.13A, 2013.

Millot, C.: The Mediterranean Sea in- and out-flows' heterogeneities. Progr. Oceanogr., 120, 254-278.

doi.org/10.1016/j.pocean.2013.09.007, 2014a.

Millot, C.: Levantine Intermediate Water characteristics: an astounding general misunderstanding! (addendum).

1015 Scientia Marina 78(2), 165-171. doi:10.3989/scimar.04045.30H, 2014b.

Millot, C., and Taupier-Letage, I.: Circulation in the Mediterranean Sea, in The Handbook of Environmental

Chemistry, Vol.5: Water Pollution, Part K, pp. 29-66, Springer-Verlag, Berlin-Heidelberg, doi: 10.1007/b107143, 2005.

Millot, C., Candela, J., Fuda, J.L., and Tber, Y.: Large warming and salinification of the Mediterranean outflow due to changes in its composition. Deep-Sea Res., 53/4, 656-666. doi:10.1016/j.dsr.2005.12.017, 2006.

Millot, C., and Garcia-Lafuente, J.: The seasonal and fortnightly variability of the Mediterranean outflow. Ocean

Sciences, 7, 1-8, doi:10.5194/os-7-1-2011, 2011.

Naranjo, C., Sammartino, S., Garcia-Lafuente, J., Bellanco, M., and Taupier-Letage, I.: Mediterranean waters along and across the Strait of Gibraltar, characterization and zonal modification. Deep-Sea Res., I, 105, 41-52. http://dx.doi.org/10.1016/j.dsr.2015.08.003, 2015.

Roether, W., Manca, B., Klein, B., Bregant, D., Georgopoulos, D., Beitzl, V., Kova, V., and Luchetta, A.: Recent changes in Eastern Mediterranean deep waters. Science 271, 333-335, 1996.

Rohling, E. J., and Bryden, H.: Man-induced salinity and temperature increases in Mediterranean deep water, J. Geophys. Res., 97, 11,191-11,981, 1992. 